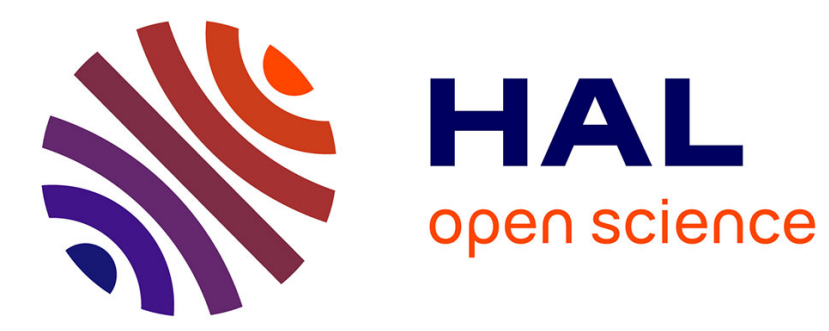

\title{
La production d'amphores à Lyon
}

Armand Desbat, Bernard Dangréaux

\section{To cite this version:}

Armand Desbat, Bernard Dangréaux. La production d'amphores à Lyon. Gallia - Archéologie de la France antique, 1997, Les productions des ateliers de potiers antiques de Lyon (2e partie) : les ateliers du Ier s. après J.-C., 54, pp.73-104. 10.3406/galia.1997.3239 . hal-01911494

\section{HAL Id: hal-01911494 https://hal.science/hal-01911494}

Submitted on 29 Jan 2020

HAL is a multi-disciplinary open access archive for the deposit and dissemination of scientific research documents, whether they are published or not. The documents may come from teaching and research institutions in France or abroad, or from public or private research centers.
L'archive ouverte pluridisciplinaire HAL, est destinée au dépôt et à la diffusion de documents scientifiques de niveau recherche, publiés ou non, émanant des établissements d'enseignement et de recherche français ou étrangers, des laboratoires publics ou privés.

\section{(이)(\$)}

Distributed under a Creative Commons Attribution - NonCommercial - NoDerivatives| 4.0 


\title{
LA PRODUCTION D’AMPHORES À LYON
}

\author{
Armand Desbat et Bernard DANGRÉAUX
}

\begin{abstract}
Résumé. La production d'amphores à Lyon a d'abord été mise en évidence par analyse et confirmée par diverses découvertes sur les siles d'ateliers, à la Muette ou la Manutention, sans que les ateliers enx-mêmes n'aient été fouillés. Quatre principaux types d'amphores ont été produits; les deux premiers s'inspirent des formes d'amphores rinaires Dressel 1 et Dressel 2/4, les deux autres, d'amphores à sauces de poissons. Les types produits mais aussi les nombreuses inscriptions peintes trouvées sur ces amphores démontrent qu'elles étaient destinées au reconditionnement de produits arrivés en arac à Lyon dans d'autres conteneurs. La production qui commence dès lépoque augustéenne se poursuit jusqu'au début du IF s., mais semble se limiter à partir du milieu du Irs. aux amphores à sauces.
\end{abstract}

\begin{abstract}
The evidence of a production of amphoras in Lyon was first given by chemical analysis and then confirmed by several discoveries on the zuorkshops of la Muette or la Manutention, but without any excazations of the kilns themselyes. Four different main types weere produced. The tuo first lypes were inspired from wine amphoras Dressel 1 and Dressel 2/4, and the other tuo from fish-sauce amphoras from Spain. The shapes of amphoras, but also "tituli picti "read on these amphoras prove that they were made to received products imported loose in other containers (barrels for instance). The production lasted from the Augustean period to the $2^{\text {nt }}$ century, but 1hen then it seems that only fish-sauce amphoras were made.
\end{abstract}

Malgré l'importance en nombre des ateliers lyonnais la diversité de leurs productions, la possibilité d'une production amphorique à Lyon n'avait jamais été envisagée de manière sérieuse. Pourtant A. Steyert (1895, p. 283) fait état, dans le quartier des Canabae, d'ateliers qui, "outre de la céramique de luxe et des poteries rouges lustrées, produisaient surtout des amphores ». Par ailleurs, en 1950, des travaux réalisés dans la cour de l'Hôtel des Postes avaient révélé une structure publiéc comme un four d'amphores (Wuilleumicr, 1952). L'information de P. Wuilleumier est la scule trace conservéc de l'intervention archéologique. L'amphore publiée ne figure pas dans le fonds ancien du Musée de la Civilisation gallo-romaine de Lyon et les archives de ce même Musée ou de la Direction des Antiquités historiques Rhône-Alpes ne possèdent aucune note ou croquis relatif aux observations enregistrées lors de l'intervention. Toutefois ces témoignages restaient peu convaincants. En effet, F. Artaud (1846, p. 150), repris par A. Steyert, avait faussement localisé dans le quartier des Canabae l'atelier de C. Attisius Sabinus, dont on sait aujourd'hui qu'il travaillait en fait à Aoste, Isère (Laroche, 1987). De même les autres vestiges signalés par Steyert peuvent aussi bien être les restes de dépotoirs ménagers que ceux d'ateliers. Quant à la découverte de l'Hôtel des Postes, où l'on recueillit des amphores de type Dressel 7/11, la description de la structure rend l'interprétation peu crédible. La présence d'un pilier central dans la chambre de cuisson est par exemple tout à fait inconnue dans les fours galloromains.

De même, bien que les fouilles d'ateliers aient livré des amphores, celles-ci avaient toujours été considérées a priori comme des importations et la question de l'origine locale ne s'était jamais posée. Pour cette raison c'est à des analyses réalisées sur un lot d'amphores augustéen trouvé à Lyon, rue de la Favorite, que l'on doit d'avoir attiré l'attention sur cette éventualité. L'analyse de Dressel 2/4 issues de ce dépôt a montré en effet l'existence d'un groupe de composition proche 


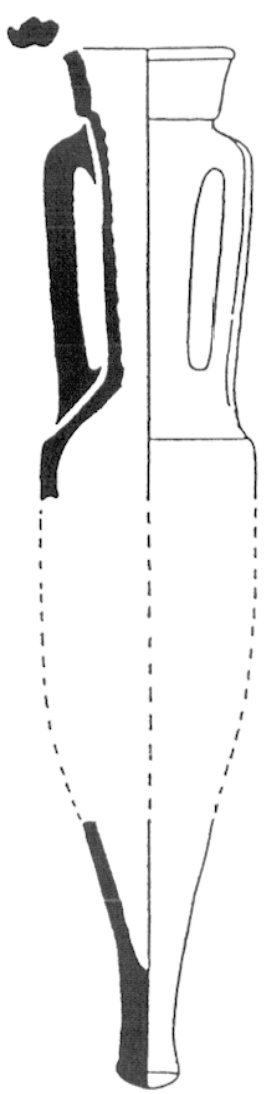

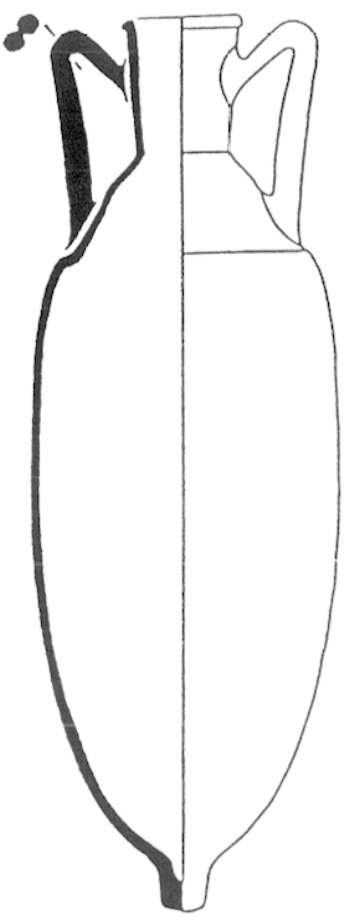

$2 \mathrm{~A}$

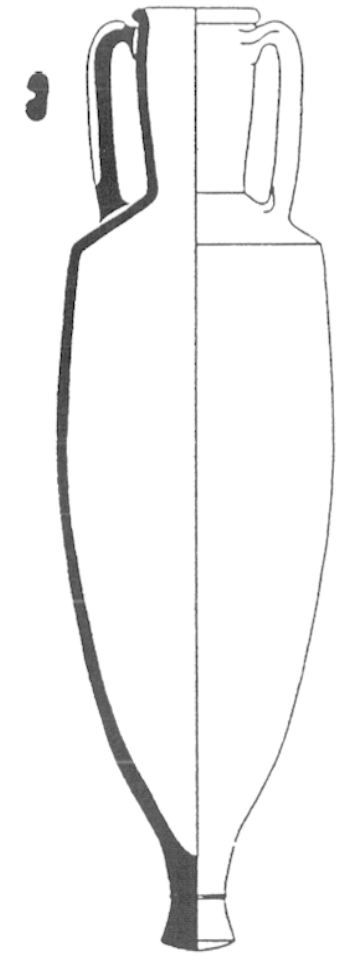

$2 B$

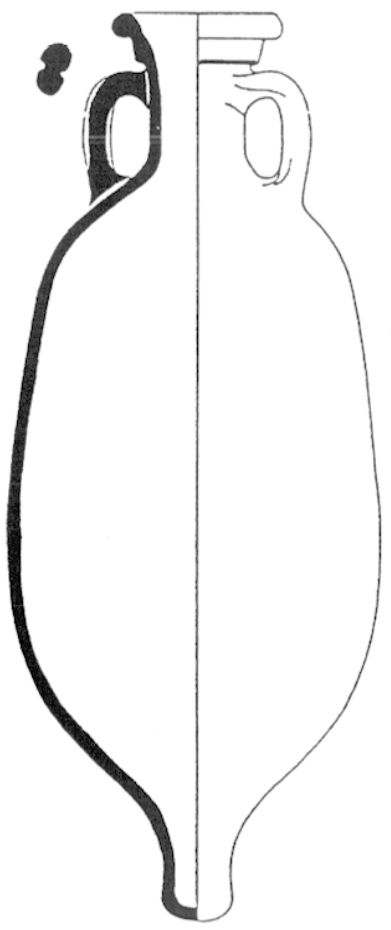

$3 \mathrm{~A}$

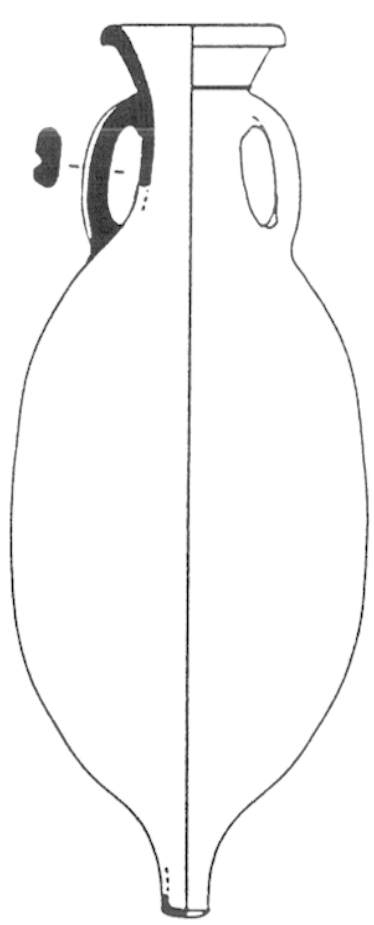

3B

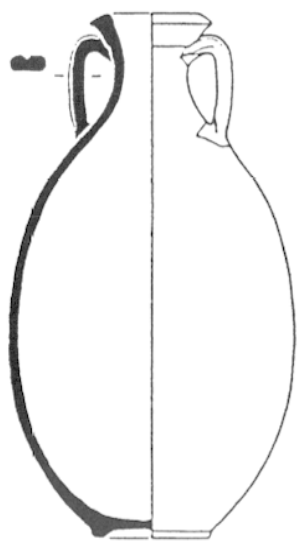

$4 \mathrm{~A}$

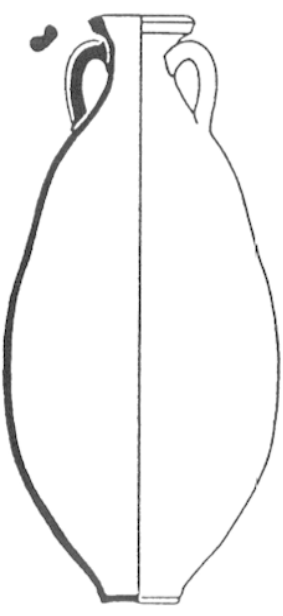

$4 \mathrm{~B}$

Fig. 22. Les quatre principaux types d'amphores produits ì Lyon (échelle: $1 / I 0$ ). 
des argiles de la Muette (Becker et al., 1986). Ce groupe, caractérisć par des pâtes beiges calcaires, à gros dégraissant sableux, comprenait des amphores de type italique mais aussi de type oriental. D'autres analyses sur des amphores du même lot qui présentaient des pâtes similaires à l'examen macroscopique, notamment un type d'amphore que l'on a pris l'habitude de désigner sous le nom de Dressel 9 similis (Paunier, 1981, p. 236), ont confirmć leur appartenance à des productions sinon lyonnaises du moins régionales. La découverte à la suite de ces premiers résultats d'un lot important d'amphores sur le site de l'Îlot 24, associant des types Dressel 1, Dressel 2/4 et Dressel 9 similis dont les analyses ont montré l'homogénéité et la proximité avec les compositions lyonnaises (Becker of al., 1986) est venue renforcer l'hypothèse d'une production d'amphores à Lyon.

Ces résultats inattendus nous ont conduits à entreprendre une recherche systématique sur les amphores régionales à partir des données fournies par les fouilles anciennes ou récentes afin de vérifier l'existence d'une production lyonnaise et de rechercher l'existence éventuelle d'autres types que ccux évoqués, en analysant des exemplaires dont les pâtes pouvaient sembler proches. Cette recherche a confirmé l'existence d'une production lyonnaise dont la typologie et la chronologie ont été précisées.

\section{TYPOL.OGIE}

Les différentes données fournies par les ateliers ( $f f$. la Muette, la Manutention), mais surtout par les sites de consommation et les analyses de pâtes ont montré que la production d'amphores lyonnaises se répartissait pour l'essentiel en quatre types (fig. 22 et 23).

\section{TYPE 1}

Il est assimilable à la forme Dressel 1. Il se caractérise par une lèvre haute, une carène très marquée, un pilon fort et des anses larges qui présentent fréquemment deux sillons (fig. 24).

L'amphore de type 1 est uniquement attestée sur le site de l'Îlot 24 . Elle y est cependant en nombre relative-
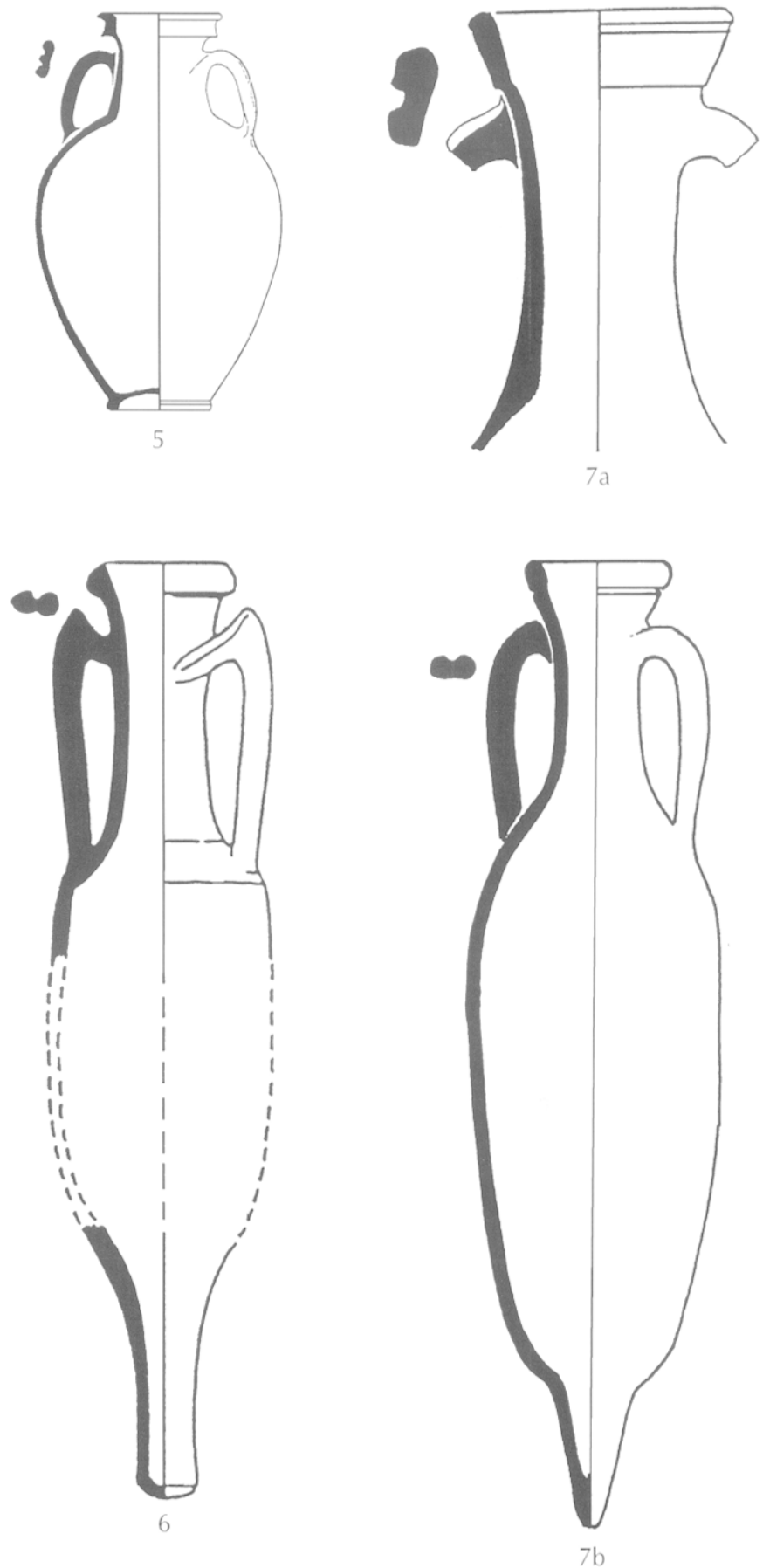

Fig. 23. Aulres types d'amphores (échelle : I/10, sauf Ta: $1 / 5$ ).

ment important : 35 exemplaires (nombre minimum d'individus) ont été inventoriés à côté d'amphores de type $2 B$ (73 exemplaires) et $3 \mathrm{~A}$ ( 11 exemplaires), ce qui constitue presque $30 \%$ du matériel amphorique répertorié (Jacquin et al., 1993). 


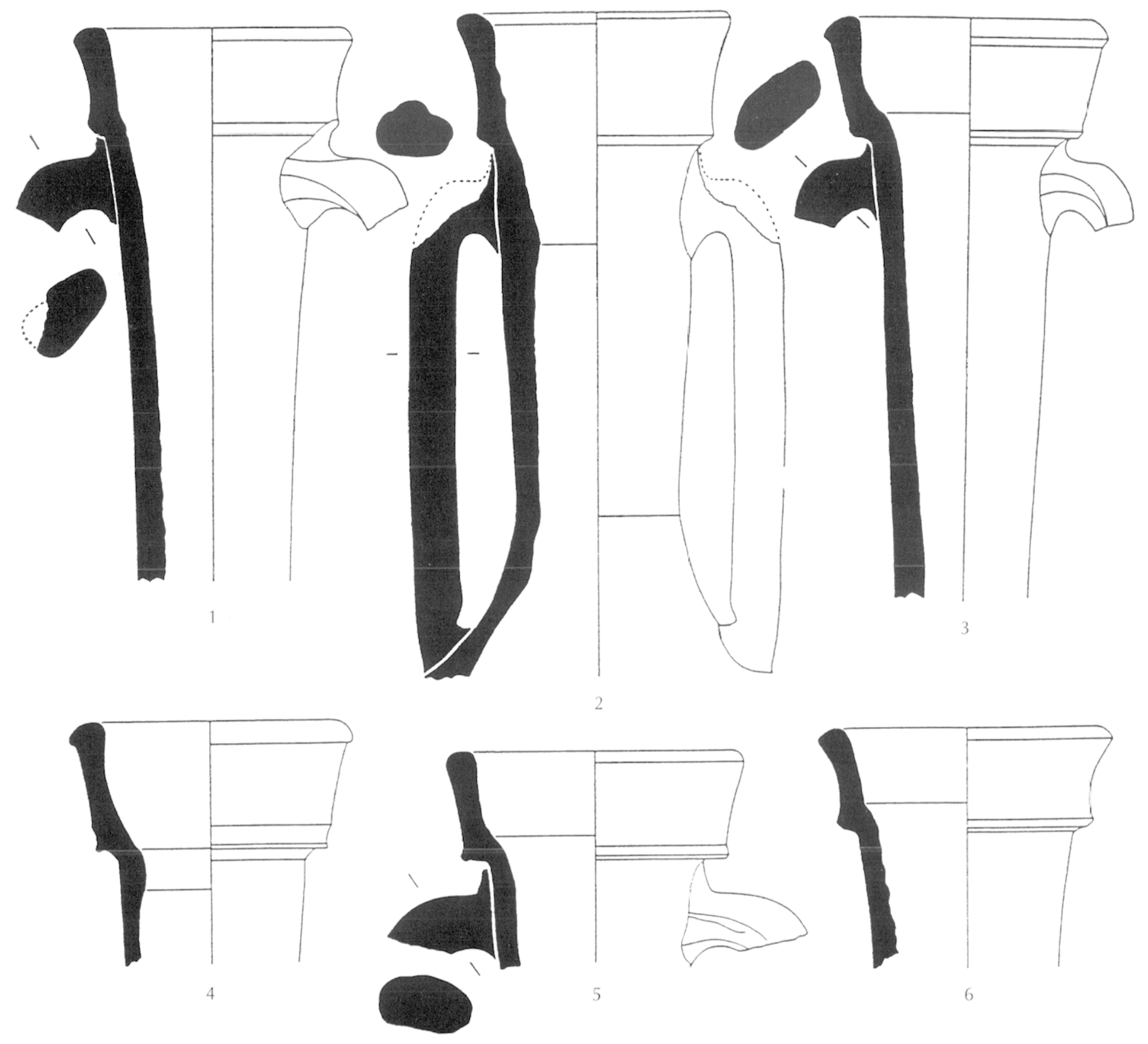

Fig. 24. Amphores Dressel I de Lyom, Ilôt 24 (Jacquin et al., 1993), (échelle : 1/4).

\section{Chronologie}

La scule information chronologique nous est donnéc par la fouille de l'îlot 24, soit une fourchette comprise entre 7 avant J.C. et 10 après J.-C. (Jacquin et al., 1993). Son absence sur les sites de consommation lyonnais, de même que sur les sites extéricurs, montre le caractère marginal de cette production. On notera également que la fabrication d'amphores inspirée de la forme Dressel 1 intervient à une époque où les importations de Dressel 1 italiques ont cessé.

\section{TYPE 2}

Il est assimilable à la forme Dressel 2/4, dans lequel on distingue deux sous-types selon qu'il rappelle l'amphore de type "Cos" (type $2 \Lambda$ ) ou "italique" (type 2B). 
Le type $2 \mathrm{~A}$ se caractérise par une épaule en forme de cloche et un petit pilon. I es anses peuvent être bifides ou pseudo-bilides.

Le type $2 B$ présente les caractéristiques suivantes : unc lève en bourrelet plus ou moins aplati; le col haut sc rétrécil à la base; un gradin marque la séparation du col avec l'épaule; celle-ci est fortement carćnée. I.es anses sont toujours pseudo-bifides, avec un sillon peu marqué sur l'extéricur; la face interne présente quelquefois un sillon. Ie pied plein présente un ressaut caractéristique que l'on retrowe sur les amphores du Falerne (Hesnard, Lemoine, 1981, fig. 11).

Ces caractéristiques très marquées n'excluent pas cependant une grande variabilité dans le détail et surtout dans les dimensions des différentes parties : hauteur des cols notamment (pl. 19), comme l'a montré l'étude détaillée des exemplaires recueillis sur le site de l'îlot 24 (Jacquin et al., 1993).

Les amphores des types $2 \mathrm{~A}$ et $2 \mathrm{~B}$ sont inćgalement représentécs. I e type $2 \mathrm{~A}$ n'est recensé que sur le site de la Favorite et en fort peu d'exemplaires ( 3 individus soit moins de $3 \%$ du lot). Le type $2 B$ est en revanche très fréquent: on en retrouve la trace sur le site d'atelier de la Muette comme sur celui de la Manutention d'où provicnt par ailleurs un des excmplaires enregistré dans le fonds ancien du Muséc. Il est bien attesté sur les sites de consommation, à la Favorite (2 exemplaires), rue des Farges, place Valmy ${ }^{8}$ et sur le site de l'Îlot 24, où il est fortement majoritaire (Jacquin et al., 1993).

\section{Chronologie}

- Ie type 2A est recensé dans les seules fouilles de la Favorite; on ne dispose pour ce type que de cette unique référence chronologique : vers 5-10 après J.-C. (Becker $\ell t$ al., 1986).

- I.e type $2 \mathrm{~B}$, signalé à la Favorite, est très présent à l'Îlot 24 , en contexte début $\mathrm{I}^{\mathrm{*}} \mathrm{s}$., il est cependant déjà attesté dans l'atelier de la Muette, vers 10 avant J.-C.

8. Le site de la place Valmy à Vaise a fait l'objet de fouilles de sauretage dirigees par Monique I ce Nezet en 1993 et 1995. L étude du matéric céramique a été réalisée par (: Bonnet. Qu'elles trourent ici l'expression de nos remerciements pour aroir pu utiliser cette documentation inédite.

\section{TYPE 3}

Il regroupe les amphores appelóes, à la suite de D. Paunicr (1981, p. 236), "Dressel 9 similis "9. On distingue là cucore deux sous-types, $3 \Lambda$ et $3 B$, délinis par la forme des lères (Dangréaux el al., 1992).

Le type $3 A$ est caractérisé par une lère formant un bourrelet en saillie au-dessus d'un bandeau détaché du col. I.es anses de section lenticulaire comportent un sillon vertical. I a panse ovoïde se termine par un pilon le plus souvent creux (fig. 25). Ce sous-type se rencontre avec de nombreuses variantes de détail, à la Muette, la Manutention, l'îlot 24, place Valmy et la Favorite (pl. 20) et 21). I a lève peut être très débordante, avec le bandeau formant un ressaut très marqué (pl. 21, n" 1 à 3).

Le $1 y p e$ s $3 \mathrm{sc}$ distingue du précédent par une embouchure plus crasée et unc lère saillante horizontale ou retombante. Ce sous-type est bien représenté à la Manutention et dans le dépotoir flavien dı Bas-deI oyasse ( $c$. Dangréaux, Desbat, 1988, fig. 18, p. 142).

\section{Chronologie}

- Ie type 3A, bien représcnté dans le matériel de la Muette, est présent dans plusieurs contextes lyonnais du début du I" s., mais se trouve aussi sur le site de la Manutention associé à des exemplaires du type 3B.

- I ce type 3B, attesté à la Manutention associć à du materiel daté de l’époque Claude-Néron (cf supra), est surtout présent dans le dépotoir flavien du Bas-de-I oyasse où est absent le type $3 \mathrm{~A}$; il semble donc succéder chronologiquement à cette première variante du type 3 .

\section{TYPE 4}

Il est représenté par une amphore de petit module, à fond plat, inconnue jusqu'à une date récente dans le répertoire. Ics amphores de petit module, type 4, ne sont pour leur part attestées qu'en un très petit nombre d'individus tant dans l'atelier de la Manutention que sur les sites de consommation tels que le Bas-de-Loyasse, les Hauts-de-Saint-Just ou la rue des Farges d'où provient le seul exemplaire complet de ce type trouvé à I yon. On peut maintenant distinguer deux sous-types.

9. Ces amphores ont été regroupés par Peacock et Milliams (1986) dans leur classe 16. Mais celle-ci regroupe aussi bien une Dressel 10 de (atalogne que le type lenoburg. 
Le type $4 \mathrm{~A}$ dont la caractéristique essentielle est unc lève avec un ressaut comme les amphores de type $3 \mathrm{~A}$. Les différents exemplaires recensés montrent une grande diversité dans le détail. La lèvre est plus ou moins

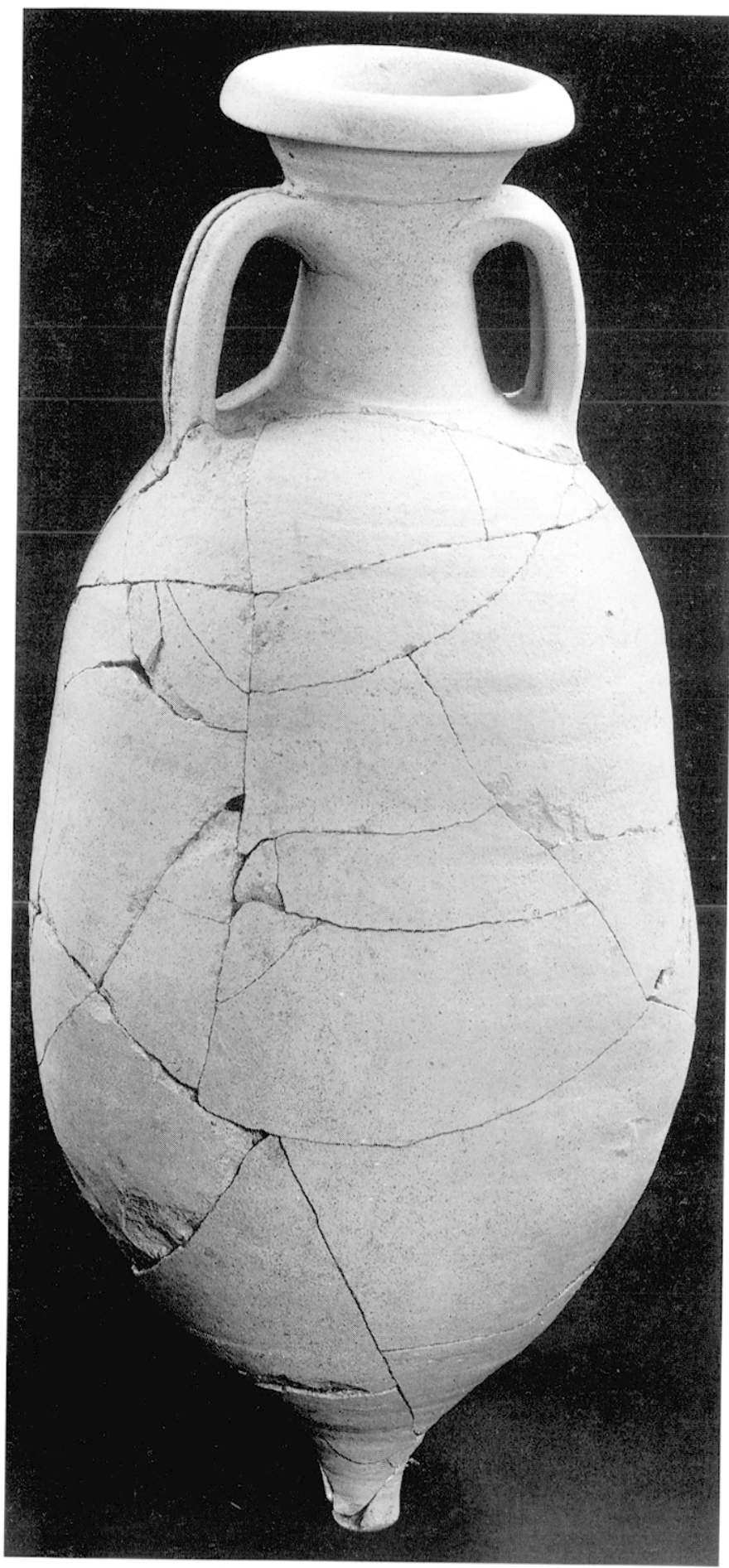

Fig. 25. Amphore de ype $3 \Lambda$ provenant des fouilles du métro de Lyon (échelle : $x 2$ ). débordante et évasée, et le ressaut plus ou moins marqué. le col est court et les anses sont généralement plates avec un sillon. I.e seul exemplaire complet provient du musée de Vienne ${ }^{10}$. Il comporte un fond plat légèrement annulairc. La rareté des profils complets ne permet pas de savoir si les fonds de la première variante sont toujours annulaires à la différence de ceux du type 4B. Ce type n'est connu qu'à de rares exemplaires sur les sites de consommation lyonnais et sur l'atelier de la Manutention.

Le type $4 \mathrm{~B}$ se distingue du type $4 \mathrm{~A}$ par un col évasé terminć par une lèvre en bourrelet. Celle-ci est le plus souvent arrondie, mais il existe des exemplaires avec une lèvre anguleuse. Les anses comportent un sillon central. I.e fond, plat, ne comporte pas de pied annulaire.

\section{Chronologie}

- Le type $4 \mathrm{~A}$ dont le témoin le plus ancien provient d'un contexte du début du I"rs. après J.-C. (pl. 26) ${ }^{11}$. La présence de ce type associé au type 4B dans le matériel de la Manutention laisse supposer qu'il est produit au moins jusqu'au milieu du I" s. après J.-C.

- Le type 4B apparaît à la Manutention ; présent au Basde-Loyasse, sur le site des Hauts-de-Saint-Just dans un contexte non daté, il est encore attesté à la fin du $\mathrm{I}^{\mathrm{r}} \mathrm{s}$. après J.-C.. rue des Farges (Desbat, 1984), (pl. 27). Il semble s'inscrire dans la même phase chronologique que le type $3 \mathrm{~B}$ : naissance vers le milieu du $\mathrm{I}^{\mathrm{er}} \mathrm{s}$. de notre ère et développement sous les Flaviens, mais pourrait se prolonger plus tardivement. Quclques exemplaires dans des niveaux de la fin du II* ou du début III' s. sont peut-être résiducls mais cela n'est pas certain.

À ces quatre types principaux on peut maintenant en ajouter d'autres qui sont moins fréquents mais dont la production est assuréc à I yon (fig. 23).

\section{TYPE 5 : DRESSEL 28 SIMILIS}

Ce type est représenté par quelques exemplaires dans l'atelier de la Muette et dans celui de la Manutention (fig. 23) (cf. supra, p. 47). Il s'agit d'une amphore à fond

10. Exemplaire d'origine incommuc, inventaire $n^{\circ} 796$ (dessin E. Bertrand).

11. Fouilles de la rue (hambonnet en 1996, sous la direction de Grégoire Ayala. 
plat, à pied annulaire. Ie col court se terminc par une lìve en poulic.

\section{TYPE 6 : DRESSEL 16}

Ce type correspond à unc amphore à garum produite à Fréjus dont on connaît un exemplaire à I ondres avec le titulus liquamen antipolitanum (Hassal, Tomlin, 1984). On ne connaît que quelques exemplaires complets de ce type peu fréquent. Il s'agit d'une amphore à col cylindrique et lève en bourrelet. I.es anses pseudo-bifides présentent un coude marqué. I a panse fuselée se termine par un pilon allongé, creux ou plein selon les cas. Il existe un risque de confusion avec l'amphore Dressel 2/4, et certains exemples ont été identifiés comme tels dans un premicr temps. C'est le cas notamment de l'amphore de Londres mais aussi pour des exemplaires de Fréjus ct de Cannes (Iaubenheimer, 1985; Laubenheimer et al., 1992).

L'analyse d'un exemplaire d'Augst a démontré que ce type avait également été fabriqué à I yon (Desbat et al., 1994).

\section{TYPE 7 : HALTERN 70 SIMILIS}

On a regroupé sous ce terme une série d'amphores qui dérivent de l'amphore de Bétique Haltern 70. On peut distinguer deux générations dans la production :

- une forme précoce imitant assez précisément le modèle bétique : lèvre oblique, anse avec un sillon central ;

- unc forme plus tardive (London 555, Augst 21) qui évolue en s'écartant du modèle initial. Il s'agit d'amphores à panse fuselée ; le col évasé présente un sillon sous la lèvre. I es analyses ont confirmé que ce type avait été produit à I yon. Un exemplaire de Saint-Romain-enGal avec l'estampille BASS a pu être attribué à I.yon, de même que d'autres exemplaires de I ondon 555 à pâte sableuse. L'existence à Nyon (Suisse) d'un excmplaire estampillé SOI.IT, marque que l'on retrouve sur plusieurs amphores dont l'origine lyonnaise a été confirmée (Desbat et al., 1994), va dans le même sens. Toutefois cette production lyonnaise ne paraît pas très importante. Il semble que la forme London 555 a été également produite par d'autres ateliers de la vallée du Rhône. Ce type se rencontre en effet le plus souvent avec des pâtes très fines, très proches par leur aspect visuel, mais aussi par leur composition d'amphores à fond plat G.3 et G4, et bien différentes des pâtes de Bétique. Il ne fait donc pas de doutc que la plupart des amphores I.ondon 555 recueillies sà ou là ont une origine gauloise et non bétique. On ne peut exclure pour autant que ce type ait été également produit en Bétique, mais cela reste à démontrer.

On peut donc distinguer deux générations dans les amphores lyonnaises.

Ia première, produisant des amphores de types 1, 2A, 2B, 3A et 4A, dont on peut situer la naissance peu avant le changement d'ère.

La seconde, représentéc par les types 3B et 4B, dont on peut fixer les débuts de production vers le milieu du I"rs. après J.-C.

On observe une grande diversité dans le détail des profils de lèvres sur les excmplaires provenant des différents sites lyonnais pour les types 3 et 4 . Cette diversité ainsi que les variations importantes constatées sur différents paramètres traduisent une production en apparence peu homogène, sans doute due à l'existence de plusieurs ateliers à I yon même (Jacquin et al., 1993).

\section{LES TIMBRES}

I.e marquage des amphores lyonnaises n'est pas systématique. Néanmoins, une dizaine de marques différentes ont été recensées, soit dans le matériel des sites lyonnais soit dans le matéricl viennois (fig. 26 et 27). Seuls deux timbres ont été trouvés en contexte d'ateliers, mais les analyses ont confirmé l'origine lyonnaise des exemplaires concernés.

Les dix marques attestées localement sont les suivantes :

\section{BASSVS (fig. 26, n"5)}

La marque figure sous la forme BAS F à la base d'une anse de Haltern 70 similis de Saint-Romain-en-Gal. On peut la rapprocher de la marque BASS sur amphore de type 3B à Genève (Paunier, 1981, n"435). 

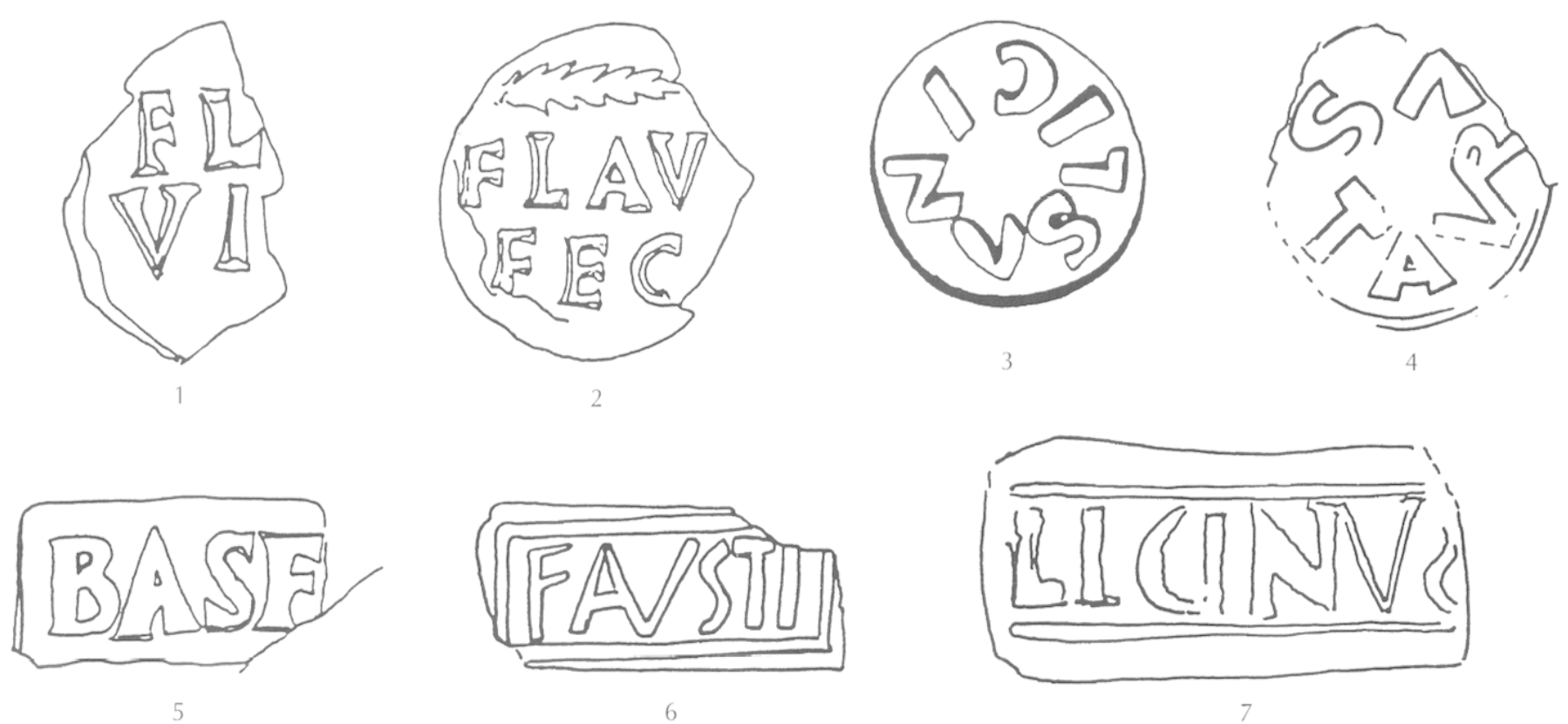

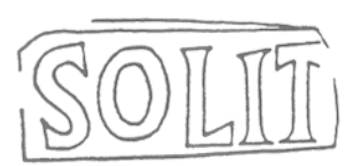

8

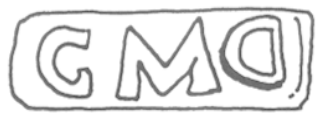

11

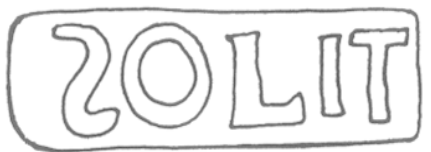

9

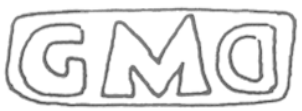

12

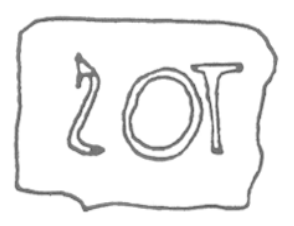

10

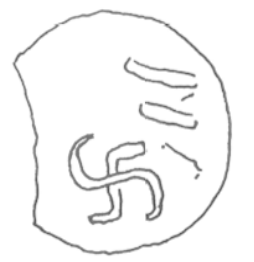

13
Fig. 26. Les limbres répertoriés sur les sites régionaux: 1, Saiml-Romain-en(ial ; 2, lyom, la Fatorite; 3, Lyon, Ilôt 24; 4, Roamme (inédit);

5, Samimt-Romain-en-(ial ; 6, 7, Lyon, la Muetle; 8, 9, 13, Lyon, fonds ancien du Musés de la Civilisation galloromaine; 10, Lyon, Bas-de-Loyasse ; 11, 12, Lyon, Hauts-de-Saint-Just (échelle: $1 / 1$ ).

\section{FAVSTVS (fig. 26, n"6)}

Cette marque figure à la Muette sous la forme FAV̂́STI dans un cartouche rectangulaire, sur un fragment de col d'amphore probablement de type 3. I a même marque existe à Avenches el Vindomissa sur amphores à garum (Callender, 1965), n"(illc).

\section{FLAVIVS (fig. $26, n^{\infty} 1$ (t 2 )}

Cette marque se rencontre sous plusicurs formes:
FI AV(IVS) marque circulaire, sur Dressel 2/4 de I yon la Favorite (Becker et al., 1986) et sur Dressel 2/4 de SaintRomain-en-Cal. On connâ̂t également la marque FI AVI a Vienne (CII, XII, 5683-110) sur col d'amphore de type incléterminé et à Coblen\%, marque circulaire sur col (Callender, 1965), n"644).

\section{G.M.D (fig. 26, n’" 11 (c) 12)}

Cette marque est commuc à deux exemplaires sur une petite amphore de type 4B (Hauts-de-Saint-Just). 

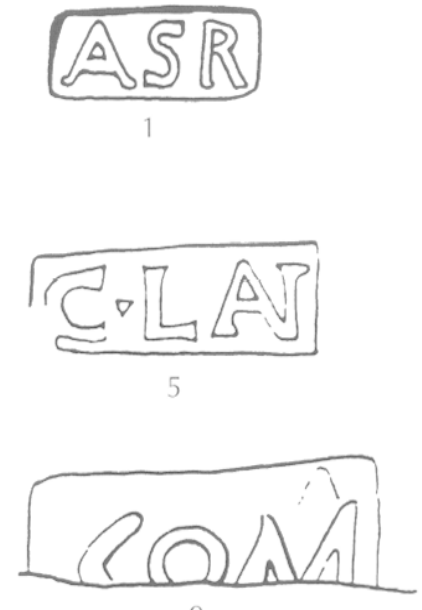

9

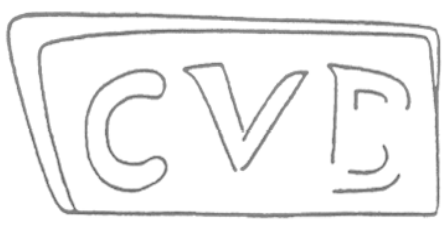

13

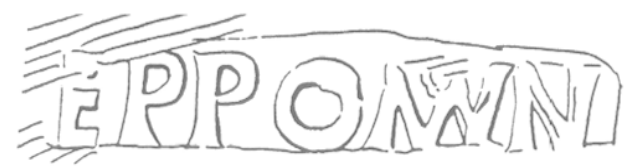

16

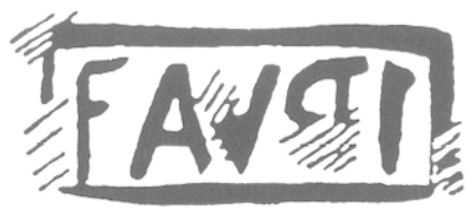

20

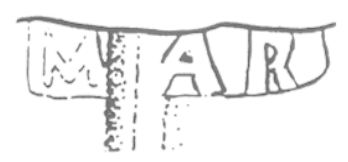

23

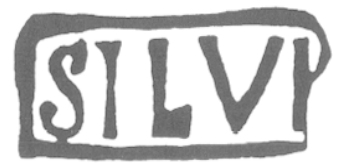

27

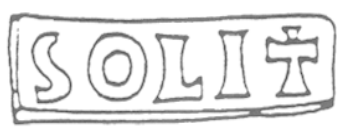

31
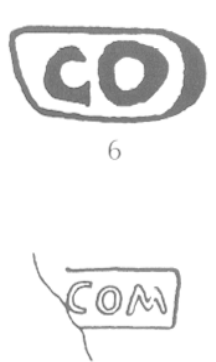

10
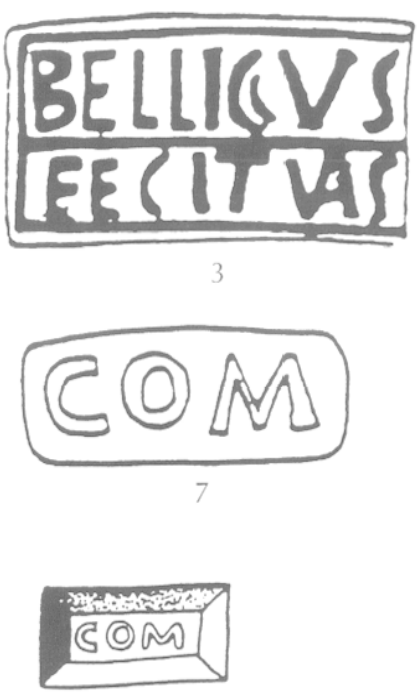

11

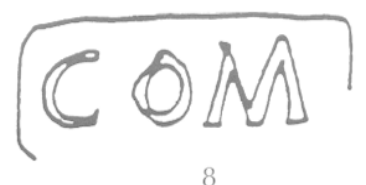

CAB

4

8

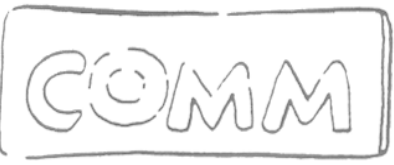

12
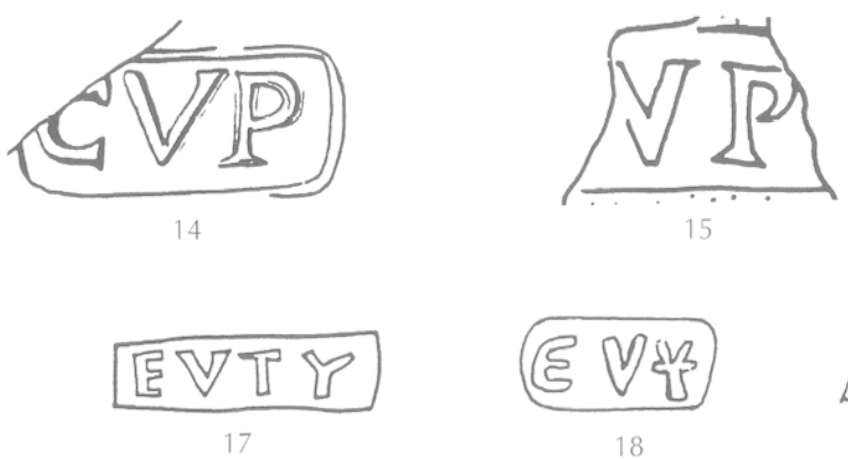

18

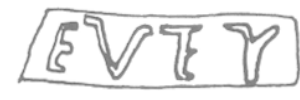

19

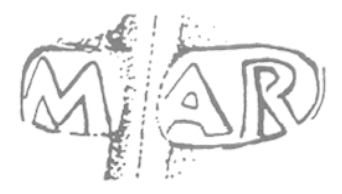

22

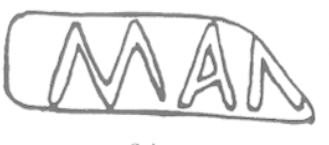

24

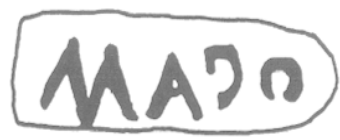

25

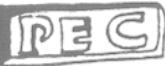

26

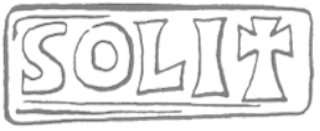

29

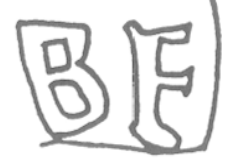

33

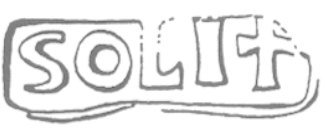

30

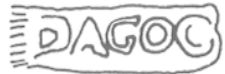

34

Fig. 27. Les timbres répertoriés sur les autres sites de consommation: I, Augst (Martin-Kilcher, 1994a) : 2, Genine (Paunie); 1981);

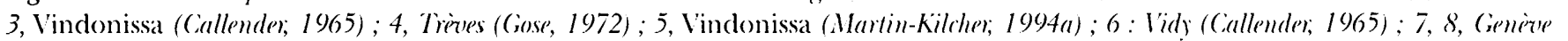

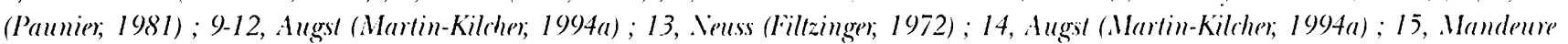
(Jeannin, Laubenheimer; 1989) ; 16, Augs (Martin-Kilcher; 1994a); 17, Aulun (inédit); 18, Berne (Eulinger; 1978) ; 19, Lenzburg (I:ulinger);

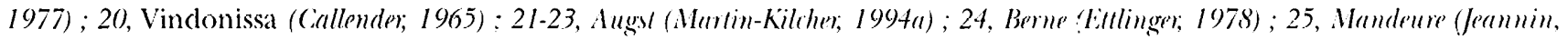
Laubenheimer, 1989) ; 26, Augst (Martin-Kilcher; 1994a); 27, Vidy (Callender; 1965); 28, Nyon (Jeamnin, Laubenheime); 1989); 29, 30, Augst (Martin-Kilcher; 1994a) ; 31, Genime (Paunier; 1981); 32, Nyon (Callender), 1965); 33, Scarponne (Baudoux, 1995); 34, Arentsburg (Laubenheimer, 1985), (échelle: 1/1). 


\section{LICINVS (fig. 26, n"7)}

Flle existe sous deux formes :

- IICINVS, cartouche rectangulaire sur col de Dressel $2 / 4$; Lyon la Muette.

- IIICINVS, cachet circulaire sur col de Dressel 9 similis type 3A; Roanne (Aulas, 1981).

\section{SOLITVS (fig. 26, n"9)}

Cette marque n'est connue à lyon qu'à un exemplaire, sous la forme SOLIT, sur l'anse d'une petite amphore de type 4, de Trion (Allmer, Dissard, 1888-1893, n"233), dont l'origine lyonnaise a été établie par analyse. En revanche elle est connue à plusicurs exemplaires avec différents graphismes sur de nombreux sites, notamment les Fins à Annecy, Augst, Nyon, Vindonissa, Vidy et Genève (Callender, 1965, n"1649 ; Paunier, 1981, n"476 ; MartinKilcher, 1994a, st. 196). Elle se rencontre sur différents types d'amphores: Dressel 9 similis, type $3 \mathrm{~A}$, type 4 et
Haltern 70 similis. (On connaît par ailleurs cette estampille sur un mortier trouvé également dans les fouilles de Trion, avec le S rétrograde (Allmer, Dissard, 1888-1893, n"151).

\section{SOTILVS SOTERICVS OU SOLITVS ? (fig. 26, n"10)}

Marque connue à un seul exemplaire: SOT, avec le $S$ rétrograde, ou SOL rétrograde, dans un cartouche rectangulaire à la base d'une anse de Dressel 9 similis type 3B (Dangréaux, Desbat, 1988). Ie rapprochement avec la marque de Solitus avec $S$ rétrograde peut faire penser qu'il s'agit d'une variante de cette signature.

\section{TAVRVS (fig. 26, n"4)}

Cette marque est connuc à cinq exemplaires identiques sous forme circulaire sur le site de l'îlot 24 (Jacquin et al., 1993). Flle se trouve sur deux types d'amphores, des Dressel 2/4 type 2B et des Dressel 9 type 3A.

\begin{tabular}{|c|c|c|c|c|c|}
\hline & $\begin{array}{l}\text { LYON } 2 \\
\text { Dr. } 2-4\end{array}$ & $\begin{array}{l}\text { LYON } 3 \\
\text { Dr. } 9 \mathrm{sim} .\end{array}$ & $\begin{array}{l}\text { LYON } \\
\text { TYPE } 4\end{array}$ & $\begin{array}{l}\text { Halt. } 70 \\
\text { similis }\end{array}$ & $\begin{array}{c}\text { Sites } \\
\text { consommateurs }\end{array}$ \\
\hline APR & & & ? & & Heitersheim \\
\hline ASR & & & - & & Augst \\
\hline BASS(VS) & & - & & - & Saint-Romain-en-Gal, Genève \\
\hline BELLICVS FECIT VAS & & - & & & Vindonissa \\
\hline BILSIII & & - & & & Vidy \\
\hline CAL & & & ? & & Trèves \\
\hline C. L. ANT. & & & ? & & Augst \\
\hline CGM & & - & & & Vidy \\
\hline $\operatorname{COM}(\mathrm{M})$ & & - & & & Vidy, Genève, Augst, Annecy, Avenches \\
\hline CVB & & - & & & Neuss, Aislingen \\
\hline CVP & & & - & & Soleure, Augst \\
\hline EPPOMVN & & - & & & Augst \\
\hline EVT ou EVTY & & - & & & Yverdon, Autun, Lenzburg \\
\hline FAVSTI & & - & & & Lyon, Avenches, Vindonissa \\
\hline FLAVI(VS) & ○ & & & & Lyon, Vienne, Coblenz, Saint-Romain-en-Gal \\
\hline GMD & & & - & & Lyon \\
\hline LICINVS & - & - & & & Lyon, Roanne \\
\hline MADO? & & & - & & Mandeure \\
\hline MAR & & - & & & Berne \\
\hline MAR (T) & & - & & & Augst \\
\hline NVS ou SAN & & • & & & Vidy \\
\hline PEC & & & - & & Augst \\
\hline SILVI(NVS) & - & - & & & Vidy, Vindonissa, Annecy \\
\hline SOLITI & & - & - & - & Lyon, Augst, Genève, Vidy, Annecy, Lenzburg, Nyon, Vindonissa \\
\hline SOT(ILVS) ? & & - & & & Lyon \\
\hline TAVRVS & - & - & & & Lyon \\
\hline TER & & - & & & Nyon \\
\hline BF & & - & & & Scarponne \\
\hline DAGOC & & - & & & Arentsburg \\
\hline RA & & • & & & Chalon-sur-Saône \\
\hline
\end{tabular}

Fig. 28. Tableaur des timbres amphoriques. 


\section{MARQUE CIRCULAIRE : swastika (fig. 26, n"13)}

Marque illisible sur col de Dressel 2/4 complète de type 2B trouvée sur le site de la Manutention (Comarmond, 1855-1857, n5 ; Desbat, 1987a).

\section{MARQUE CIRCULAIRE ILLISIBLE}

Marque illisible sur col d'amphore Dressel 9 similis de type 3A, inédite (musée de Lyon).

La typologie des amphores et la nature des pâtes permettent d'attribuer aux productions lyonnaises, ou du moins régionales, d'autres estampilles rencontrées sur les sites de consommation, en particulier sur les amphores de type $3 \mathrm{~A}$ ou 3B, mais aussi sur des amphores de type 4 (fig. 27 et 28).

APR : sur amphore de type 4 (Heitersheim, BadenWurtemberg) (Martin-Kilcher, 1994a, note 449).

ASR : cstampille relevée à Augst à la base d'unc anse d'amphore de type 4 (Martin-Kilcher, 1994a, st. 187). Il faut signaler qu'un mortier lyonnais a livré la marque ASRCO.

BELLICVS FECIT VAS : sur col d'amphore à Vindonissa (Callender, 1965, n"186). Callender avait proposé la lecture Vas (ione) et une origine de Vaison. L'analyse de cet exemplaire a conclu à une origine lyonnaise (Desbat $e t$ al., 1994).

CAL : (Callus ?) sur anse d'amphore de type 4B à Trêves Altbachtal (Gose, 1972).

C.L.ANT : sur anse d'amphore type 4 à Vindonissa (Martin-Kilcher, 1994a, abb. 156). On peut rapprocher cette marque de l'estampille C. ANT.C.F ? trouvée sur un morticr lyonnais.

CGM : sur amphore de type 3 à Vidy.

CO : à Vidy (Callender, 1965, n"410). Il faut peut-être rattacher cette marque à la même fabrique que les marques suivantes, toutefois l'estampille sur mortier qui associe ASR et CO permet d'autres possibilités.

COMM ou COMN ou COM : (Communis ?) sur col et sur une anse de Dressel 9 similis à Genève (Paunier, 1981, n" 436 et 437) et à Augst à plusieurs exemplaires, avec des tailles et des graphies différentes (Martin-Kilcher, 1994a, st. 193a-193d).

CVB : sur une lèvre de type 3A à Neuss (Filtzinger, 1972). CVP : à Augst sur anse d'une amphore de type 4B (Augst
17) (Martin-Kilcher, 1994a, st. 188), à Soleure ct Mayence.

EPPOMVNI : à Augst (Martin-Kilcher, 1994a, st. 194).

EVT, EVTY : (Eutyches?) sur anse d'amphore de type 4 à Autun el à Berne (Ettlinger, 1978). On peut rapprocher unc autre marque relevée à la base d'une anse d'amphore de type 3B à Lenzburg (Ettlinger, 1977) qu'il faut probablement lire également EVTY.

MADO ? : sur col à Mandeure (Jcannin, Laubenheimer, 1989). On peut se demander s'il ne faut pas corriger la lecture en MAR. O (F), le graphisme de cette marque étant très voisin de la marque de Soleure et la marque MAR OF étant signalée par Callender $\left(1965, n^{\circ} 1019\right)$ sur Dressel 2/4.

MAR : sur anse en deux exemplaires à Augst (MartinKilcher, 1994a, st. 195̄b) et à Bern (Ettlinger, 1978). La même marque avec une forme très proche est signalée par Callender à Londres (1965, n"1019).

MARTF : (Martialis ?) sur anse également à Augst (Martin-Kilcher, 1994a, st. 195a). Il faut signaler que la marque MARTIALIS. F est connue à Genève sur mortier (Paunier, 1981, n' 499).

PEC : sur anse d'amphore de type 4, à Augst (MartinKilcher, 1994a, st. 186).

SILVINVS : la marque est connue sous la forme SILV à Annecy (Callender, 1965, n"1625a), SILVI à Vidy (Paunier, 1981) et Vindonissa (Callender, 1965, n"1625c), SILVIN à Annecy. Il faut distinguer cette marque de l'estampille SIIVINVS F. connue à Avenches sur anse de G.4 (Laubenheimer, 1985, p. 433).

TER : sur amphore de type 3 à Nyon (Callender, 1965, $\mathrm{n}^{\circ}$ 1709). On connaît par ailleurs la marque TERTI à Genève.

.BF : sur le col d'une amphore de type 3 à Scarponne (Baudoux, 1995, fig. 35, n" 10) 12 .

.DAGOC : sur le col d'une amphore de type 3B à Arentsburg (Holwerda, 1923; Laubenheimer, 1985, fig. $\left.6, \mathrm{n}^{\prime \prime} 8\right)$.

.RA : sur col de type 3, à Lux (Musée de Chalon-surSaône, inédit).

.VP. : à Mandeure (Jeannin, Laubenheimer, 1989), peutêtre s'agit-il de CVP ?

12. Juliette Baudoux publie une autre estampille I.V.N (a) situéc sur l'anse d'une amphore de Biesheim, classée dans le groupe des Dressel 9 similis (Baudoux, 1995, fig. 35, $\mathrm{n}^{\circ} 8$ ). Toutefois, ses caractéristiques typologiques paraissent plutôt la rattacher au type I enzburg. 
Marque circulaire illisible sur col d'amphore à Genc̀ve (Paunier, 1981, "1"479).

Trois remarques sont à formuler :

1. I a marque la plus fréquente est celle de Solitus, connuc ares plusicurs graphismes. Celle-ci se retrouve sur différents types d'amphores mais également sur mortier. D'autres marques offient des analogies avec les estampilles rencontrées sur les mortiers. Ie timbrage sur les morticrs lyomnais n'est pas du tout sy'stématique, mais ces quelques parallòles confirment les rapports étroits entre la production des amphores et celle des mortiers.

2. I a totalité des timbres circulaires sur col figurent sur des modèles de la première génération c'est-à-dire sur les types $2 \mathrm{~A}, 2 \mathrm{~B}$ et $3 \mathrm{~A}$. Ils sont inconnus sur les types de la seconde génération pour lesquels seuls sont répertoriés des timbres dans un cartouche rectangulaire apposé le plus souvent à la base de l'anse, plus rarement sur le col ou la lère.

3. I a présence d'estampilles circulaires sur plusieurs amphores lyommaises pourait laisser supposer qu'il s'agissait d'un ćlément distinctif de la production lyonnaise. On sait aujourd'hui qu'il n'en est rien (Jacquin ef al., 1993). Il n'empêche que cette forme de timbrage reste un élément important de la typologic lyonnaise.

\section{A QUESTION DES IMITATIONS}

I a production lyonnaise n'est pas la seule à s'être inspirée de modèles fabriqués en Italie ou dans les provinces. En (iaule, 21 autres ateliers sont actuellement recensés (fig. 29); Dressel l ou Dressel 2/4 figurent, comme à Iyon, parmi la production de quelefues-uns d'entre cux :

Corncilhan (I aubenheimer, 1985),

Crourilles (Schwcity al., 1986),

Marseille, butte des Carmes (Bertucehi, 1990),

Montans (inćdit),

Ponteilla (I aubenheimer, 1989a)

Sainte-Cécile-les-Vignes (Meffice, Meffre, 1992),

Saint-Just, Ardiche (I aubenheimer et al., 1989),

Saintes (incedit),

Sens (Perrugot, 1996),

Velaux, Moulin du Pont (Ichernia, Villa, 1977),

Velaux, plaine de I evau (I aubenheimer, 1985).

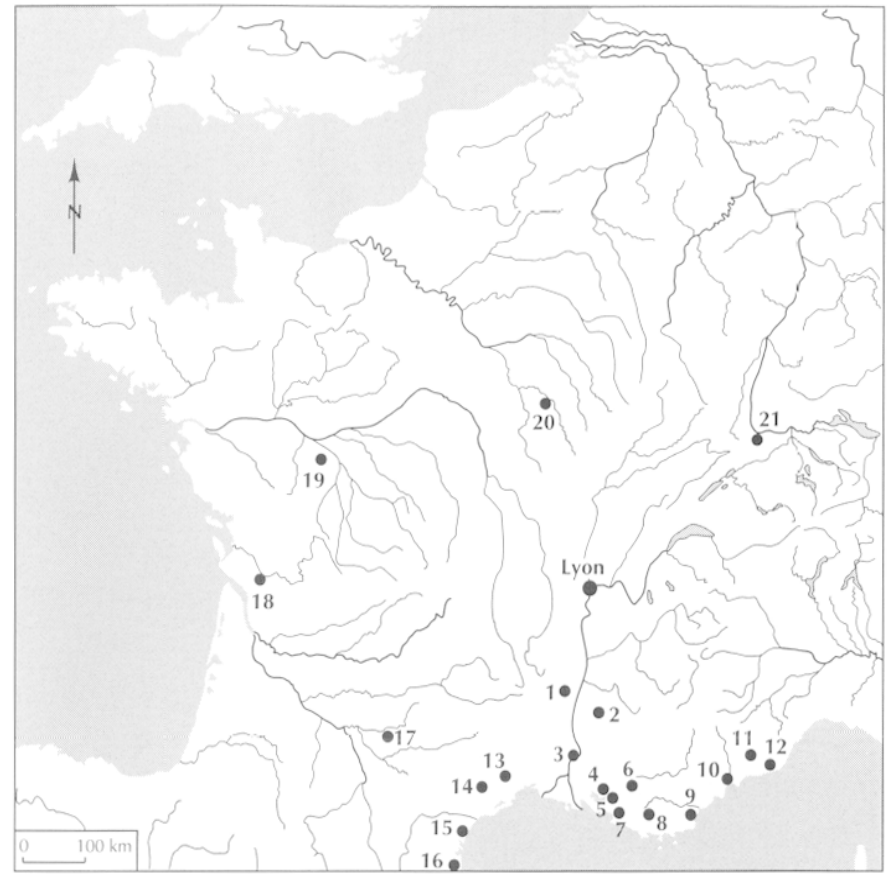

Fig. 29. Carte des aleliers ayant produil des imitations d'amphores d'inspiration ilalique ou hisponique : I, Saint-Just, Ardeche;

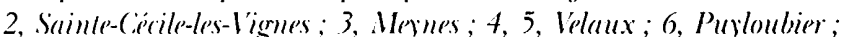

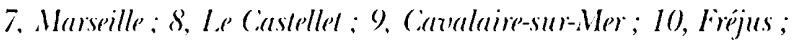

11, Cannes ; 12, Antibes ; 13, Aspiran; 14, Comeilhan;

15, Sigeran ; 16. Ponteilla ; 17. Montans; ; 18, Saintes ;

19. Mougon; 20, Soms ; 21 , Augst.

\section{LES DRESSEL 1}

I a production en Gaule de Dressel 1 n'est attestée, hors de Iyon, que dans le seul atelier de Saint-Just, Ardèche. Bien que le modèle fabriqué ne soit connu que de façon fragmentaire, on peut distinguer deux variantes. Dans la première, la lève présente une inflexion externe (fig. 30, n" 1 et 2); dans la seconde au contraire (fig. 30, n" 3 et 4), l'inclinaison de la levre forme un bord rentrant. Dans les deux cas, la lève est haute (autour de $6 \mathrm{~cm}$ ) quoique légèrement moins élevee dans la seconde variante.

Ia première de ces variantes se rapproche quelque peu de la production lyomaise mise au jour sur le site de l'îlot 24 (Jacquin et al., 1993) par la hauteur de la levre et l'inflexion externe de celle-ci, toutefois moins prononcéce. Hlle s'en sépare pourtant par un creux interne au niveau de la liaison col/leve : très nettement visible sur la plupart des modèles lyomnais (29) des 35 exemplaires recensés), il est fort peu perceptible dans la production de l'atelier ardéchois. 


\section{LES DRESSEL $2 / 4$}

L.es Dressel 2/4 produites en Gaule présentent des caractères typologiques très diversifiés. I a fabrication n'est pas standardisée et les modèles varient d'un atelier à l'autre, voire entre deux productions d'un même atelier (fig. 30). Au demeurant, cela ne peut surprendre si l'on se réfère au nombre de formes déjà inventoriées dans l'ensemble de la production, tant italique que provinciale, des amphores Dressel 2/4 (Hesnard, 1981).

Les rares exemplaires complets soulignent assez les différences typologiques rencontrées. Les deux variantes fabriquées à Crouzilles sont fort dissemblables (pl. 28, n" 12 et 13) : lèvre avec ou sans ressaut interne, panse cylindrique ou ovoïde, pilon plein ou creux, etc., même chose pour les deux variantes de Fréjus (pl. 28, n"1 10 et 11). L'atelier de Sainte-Cécile-les-Vignes fabrique quant à lui un modèle qui, avec un petit pilon plein, un col court muni d'anses bifides et terminć par une mince lèvre arrondic (pl. 28, n“7), se distingue aisément des autres productions recensées.

I.es éléments fragmentaires issus des autres ateliers ajoutent encore à la diversité. Les cols peuvent être cylindriques comme à Marseille (pl. 28, n"3), tronconiques comme dans les deux ateliers de Velaux (pl. 28, n" 1 et 2) ou bitronconiques comme à Corncilhan (pl. 28, $\mathrm{n}^{\mathrm{m}} 8$ et 9), atelier dans lequel on rencontre des anses aux variantes bifides et pseudo-bifides. Cet atelier traduit bien la diversité de la production des amphores Dressel 2/4 : des deux variantes produites, l'une (pl. 28, n"1) présente un col bitronconique et des anses pseudobifides, l'autre (pl. 28, n"2) offre un col tronconique et des anses bifides.

Dans cet ensemble, la production lyonnaise se distingue par le fait de reproduire des modèles connus par ailleurs.

\section{LE TYPE 2A}

Les caractères typologiques définissant ce modèle (fig. 31, n"1) reprennent ceux appartenant à la classe des amphores dites de Cos définic par A. Hesnard (1981): col en cloche, anse formant un coude prononcé et petit pilon. L'origine orientale de la sćrie initiale suggérée, notamment, par une inscription peinte sur une des amphores de même type découvertes à Pompei (fig. 31, n"2) a été confirmée par des analyses physico-chimiques
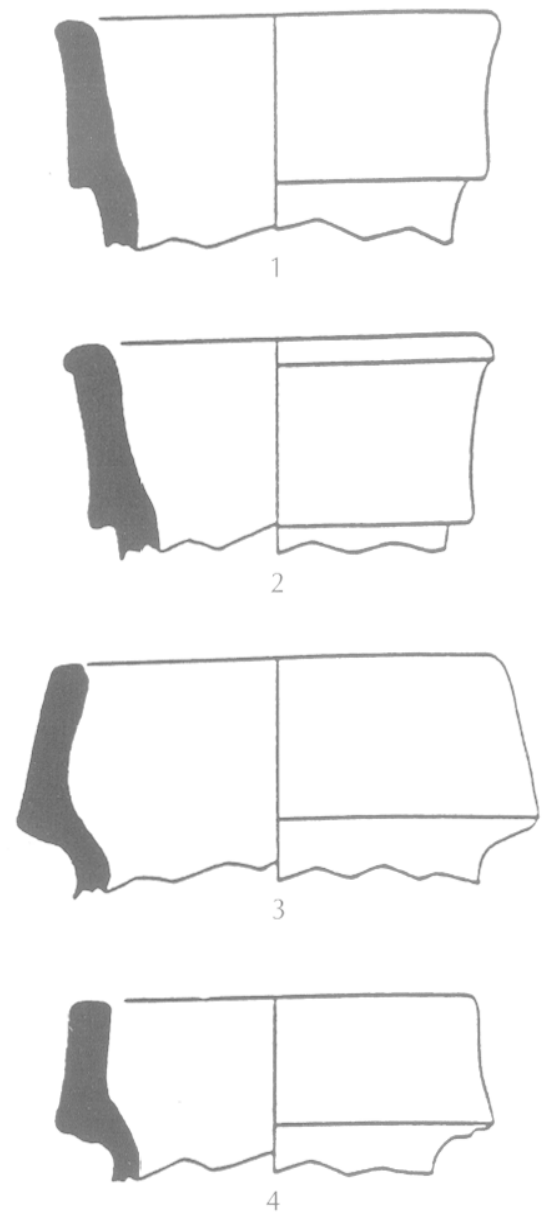

Fig. 30. Amphores Dressel 1 de latelier de Saint-Just, Ardiche' (Lanbenheimer et al., 1989), (échelle: 1/4).

effectuées sur des exemplaires semblables (fig. 31, 11"3) recueillis à Lyon sur le site de la Favorite (Desbat, Picon, $1986 a)$.

\section{LE TYPE 2B}

Sa morphologic (fig. 31, n"4) est tout à fait comparable à celle d'un groupe d'amphores reconnu à Pompci (Panclla, Fano, 1977) et rangé dans unc série originaire de Campanic du Nord (Hesnard, 1981). I.e ressaut en pied le rattache même de façon plus précise encore à certaines productions de la région du Faleme, ainsi qu'ont pu le mettre en évidence des prospections suivies d'analyses physico-chimiques (Hesnard, Lemoine, 1981) sur les échantillons récoltés (fig. 31, n“6).

Ce modèle de Campanie du Nord se sćpare toutefois du type 2B lyonnais par ses aspects dimensionnels et 

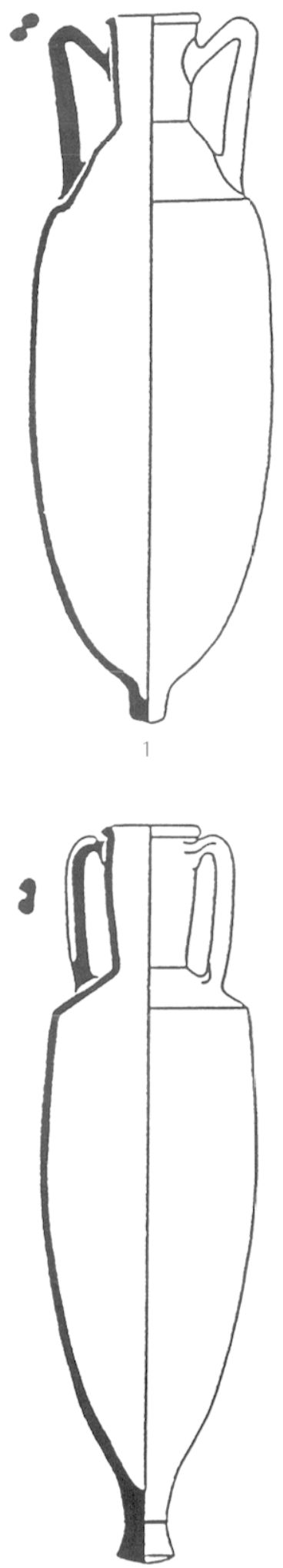

4

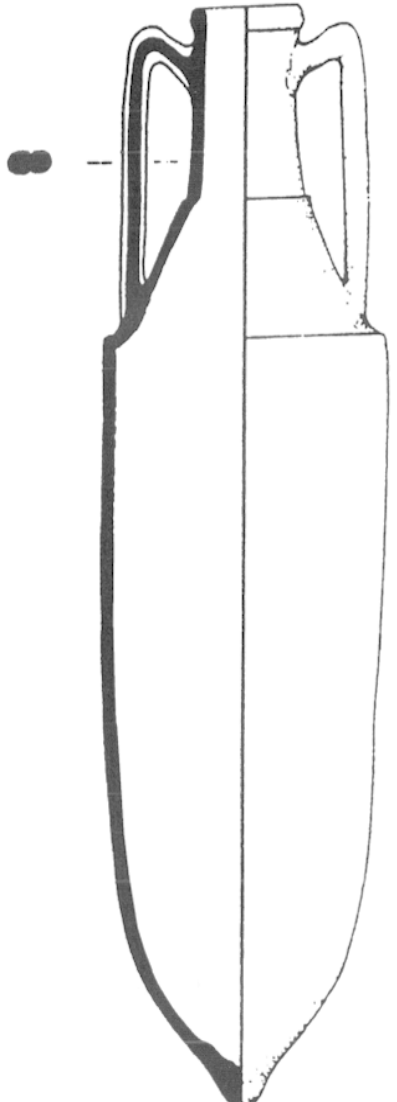

2

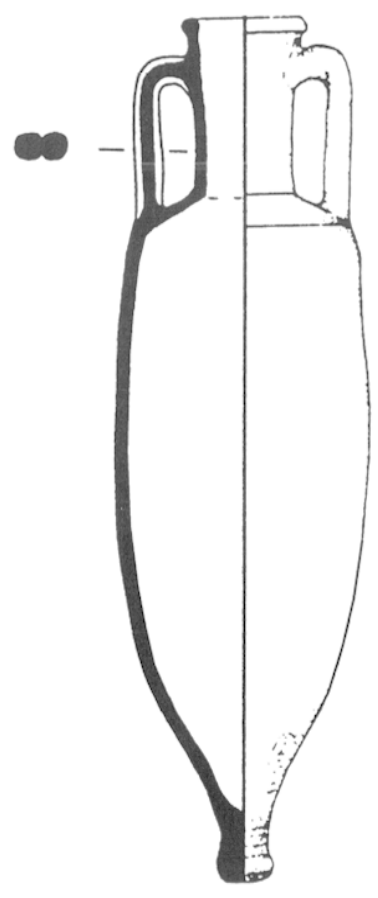

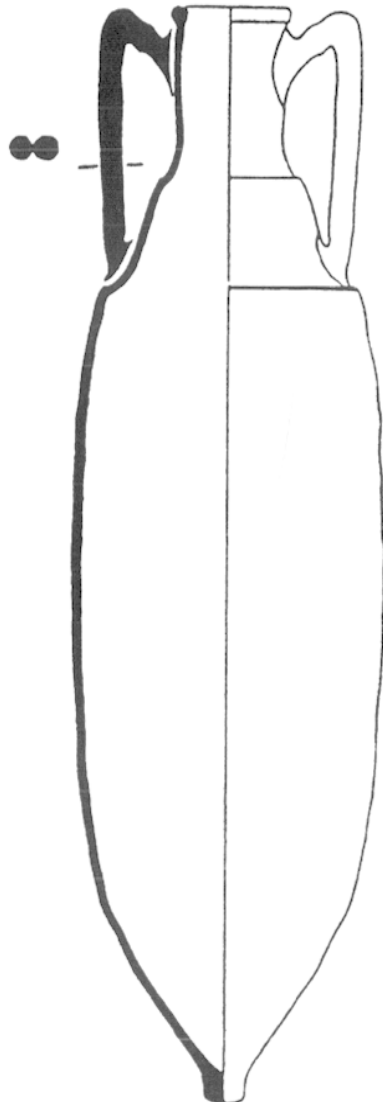

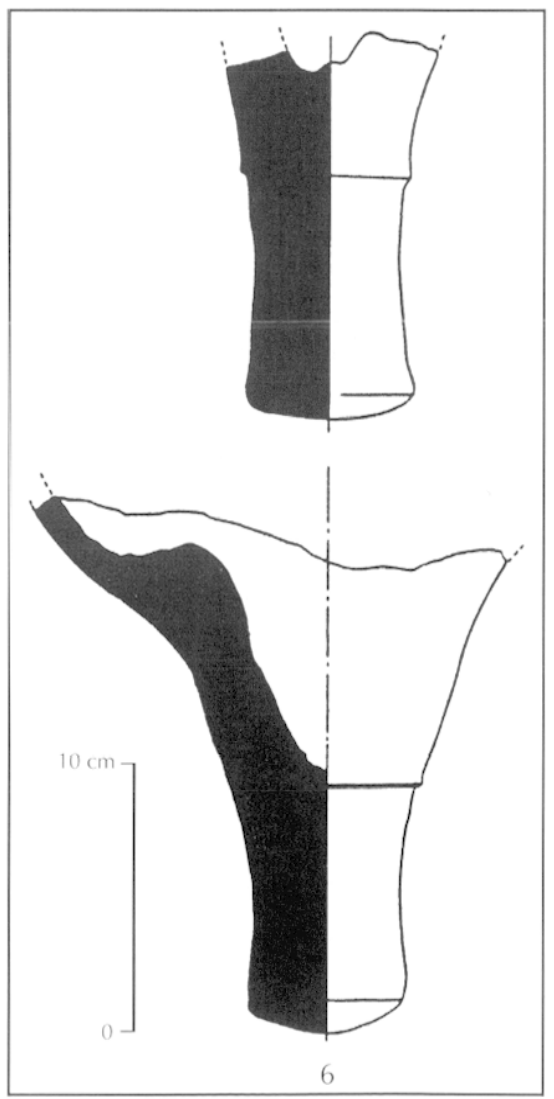

Fig. 31. Comparaison des amphores Dressel 2/4 lyonnaises aver les modiles orientaux ou italiques : I, amphore de Lyon de type $2 A$, dépôt de la Favorile (Becker et al., 1986) ; 2, amphore de type Cos provenant de Pompéi (Panella, Fano, 1977); 3, amphore de lype Cos provenaml de Lyon, la Fauorite (Desbat, Picon, 1986a) ; 4, amphore de Lyon de type 2B; 5, amphore de Campanie du nord, provenant de Pomprii (Panella, Fano, 1977); 6, pieds d'amphores Dressel 2/4 des ateliers du Falerne (Hesnard, I.emoine, 1981), (échelle : 1/10, sauf le n"6). 
quelques-uns de ses critères typologiques : anses bifides, attaches supérieures des anses nettement détachées du niveau inférieur de la lère, estampille située sur le pied pour les excmplaires timbrés (Jacquin et al., 1993). On a déjà pu voir en effet ( $f$. supra, typologie) que pour ce type 2B, les anses sont pseudo-bifides, rattachées directement sous la lèvre; aucun en outre ne présente de timbre sur le pied : les exemplaires lyonnais estampillés porte leur timbre sur le col dans un cartouche le plus souvent circulaire (l'estampille de IICINVS constituant une exception), ce qui est tout à fait ćtranger à la production campanienne de la région du Falerne.

On a pu voir que la production d'amphores inspirées de modèles italiques et/ou hispaniques n'appartenait pas aux sculs ateliers lyonnais. I a plupart des "imitations" gauloises sont précoces et ont une durée de vie assez courte ainsi qu'une diffusion limitée. C'est le cas pour les Pascual 1 et Dressel 2/4 de Marseille, pour les Pascual 1 d'Aspiran et de Montans, pour les Dressel 2/4 lyonnaises.

Par certains côtés on peut rapprocher ce phénomène avec la multiplication des ateliers d'imitations de sigillée à la fin du I" ${ }^{\mathrm{w}}$. avant J.-C. Mais alors que les imitations de sigilléc reproduisent fidèlement le répertoirc italique, les amphores ne sont le plus souvent qu'une copie grossière du prototype. Pour la Gaule, la production lyonnaise des Dressel 2/4 est la seule à rappeler nettement des modèles dont l'origine (Cos, Falerne) est commue. En ce sens, elle est la scule pour laquelle on peut parler d'imitation.

L'existence de ces "imitations " oblige à s'interroger sur la notion d'imitation ou de copie mais pose surtout la question du contenu et de l'origine des produits transportés dans ces amphores.

On peut distinguer des degrés divers dans la copic ou l'imitation, depuis une évocation qui s'inspirc asse $\%$ librement de la forme, jusqu'à une copie conforme qui respectera même les détails. I a copie ou l'imitation correspond en effet à des phénomènes divers. Il peut s'agir en premier lieu d'une simple question de mode. Telle forme est imitée parce qu'elle plaît ou qu'clle correspond à un produit à la mode. I a copie peut aussi être destinéc à permettre au client de se procurer à moindre prix un produit onéreux. Elle peut encore être une véritable contrefaçon, un faux pour tromper, destiné dans ce cas à abuser le client. Dans cette dernière éventualité, la copie se doit d'être la plus fidèle possible, à moins de supposer que le consommateur, ou le fabricant, n'ait qu'une idcé vague du produit originel. Faut-il expliquer la production des imitations par un de ces phénomènes ou tous à la fois, ou y a-t-il encore d'autres possibilités?

S'il s'était agi de génćraliser un modèle, un scul type, Dressel 2/4 de type Cos ou de type Falerne, aurait suffit. Or les deux types, Cos et Falerne, existent conjointement ainsi que l'ont mis en évidence les fouilles de la Favorite. Nous écarterons donc la première hypothèse.

Si l'amphore lyonnaise du type 2B est assez proche du modele originel, elle se distingue cependant de son homologue campanien, par ses dimensions, la facture des anses et le timbrage. Nous ne sommes donc pas en présence d'unc copic parfaite. Ia chose est encore plus flagrante pour les amphores à garum lyonnaises qui s'inspirent très librement des prototypes hispaniques. Dans tous les cas, il semble difficile de parler de contrefaçon. Même lorsque la copie est proche de l'original, comme les Dressel 2/4 lyonnaises qui ront jusqu'à reproduire l'anneau du pied que l'on trouve sur les amphores du Falerne, elle s'en distinguc par la pâte, alors qu'il cut été facile aux potiers de choisir des terres permettant de mieux imiter le produit. De même la présence d'estampille, même si elle n'est pas généralisée, contribue à distinguer les imitations lyommaises des prototypes qu'elles sont censées copier. Il faut donc écarter l'idée que ces copies aient été destinées à abuser les consommateurs.

Pourquoi alors copier ou s'inspirer de formes existantes plutôt que d'essayer de créer un modèle original ? I.e phénomène de mode paraît le plus plausible mais il n'explique pas tout. I e fait que les ateliers italiques abandonnent la forme Dressel 1, au profit de la Dressel 2/4 qui imite l'amphore de Cos, et le fait que cette Dressel $2 / 4$ devienne le modèle d'amphore vinaire le plus répandu produit dans presque tout le monde romain semblent bien un phénomène de mode. De même, à partir de la fin du I's. après J.-C., l'amphore à fond plat devient le type d'amphore vinaire le plus courant en Occident.

En revanche, la production par un même atelier de plusicurs imitations, notamment de plusicurs types d'amphores vinaires, comme c'est le cas à Lyon ou à Marseille, ne peut pas s'expliquer uniquement par un simple phénomène de mode. On doit donc envisager d'autres explications. Une possibilité scrait que l'imitation de formes bien connues du monde méditerranéen soit destinéc à valoriser un produit médiocre par un emballage évoquant un contenu prestigieux, comme par exemple une piquette gauloise dans une amphore de type Falerne. 
I a volonté de faire un objet reconnaissable par l'acheteur nous parât être l'hypothèse à retenir.

Une situation quelque peu semblable se rencontre d'ailleurs plus tard entre le milieu et la fin du II"s., dans les atclicrs rhénans. Colui de Rhcinzabern produit alors des amphores assimilables à la Dressel 20 " par la parfaite adéquation de leur forme" (Baudoux, 1995, p. 106). Malgré quelques variantes de détail, dans la forme de la lève notamment, la volonté d'imiter le modèle de Bétique est d'autant plus évidente que cette production est timbrée sur l'anse. I'estampille a toutefois une signification différente: "clle sert ici à reconnaître l'objet façonné par le potier et non le fundus ou la figlina" (idem). Ià aussi donc il y a volonté de rappeler un modèle connu avec la possibilité pour l'acheteur de distinguer le type gaulois du type ibérique.

L'exemple des amphores à garum de Iyon atteste qu'une partie au moins de ces imitations était destinéc au reconditionnement de produits importés en vac (Desbat, 1991). Ices nombreux tituli relevés sur les amphores Dressel 9 ou 10 similis (Lyon $3 A$ et 3B), qui désignent le contenu Garum Flos, Muria Hispana, Garmm Hispanum, ne laissent pas de doute. Lne autre hypothèse serait donc que la forme des amphores correspond à la nature mais aussi à l'origine du produit. Ainsi le garum importé de la péninsule ibérique est-il conditionmé à Iyon dans des amphores qui copient les formes hispaniques. Dans cette hypothèse les amphores Haltern 70 similis ou Iondon 555, dont les tituli désignent un contenu identique à celui des Haltern 70 de Bétique (olives conservées dans des vins doux), pourraient contenir des olives de Bétique.

Il semble qu'il existe toutefois plusieurs cas de figure. Il est difficilement concevable que les Dressel 2/4 de Iyon aient pu contenir du Falerne ou du vin de Cos importé en vare. Dans ce cas il se pourrait que la forme de l'amphore ne traduise pas l'origine du vin, mais peutêtre sa qualité : vin préparé à l'eau de mer selon la recette de Cos?

L'analyse de l'amphore de londres avec l'inscription Liquamen Antipolitanum a montré que celle-ci avait été fabriquée à Fréjus, ce qui signifie que le garum d'Antibes pouvait être conditionné à Fréjus. Mais peutềtre le même garum ou des produits comparables ont pu être conditiomnés à I yon, si l’on se réfère à l’origine lyomnaise d'une amphore Dressel 16 trouvé à Augst (Desbat el al., 1994).

\section{A QUESTION DU CONTENU}

Cette question a déjà fait l'objet d'un développenent détailló (l)angréaux, à parâtre). Nous ne rappellerons donc ici que les résultats de cette cutude.

\section{LA NATURE DU CONTENU}

\section{LES AMPHORES DE TYPES 1 ET 2}

Aucun titulus n'a été relevé sur ces amphores. Mais les Dressel 1 et Dressel 2/4 dont s’inspirent les types 1 et 2 sont des amphores vinaires certifiées par les inscriptions peintes ou témoignages archéologiques directs. On peut ainsi raisommablement admettre le vin pour contenu des amphores correspondant à ces types.

\section{LES AMPHORES DE TYPES 3 ET 4}

Ic contenu est assuré par une série d'inscriptions peintes sur les cols d'amphores des types 3A, 3B, 4A et 4B.

Un titulus figure sur le col d'une amphore de type 3B provenant du dépotoir du Bas-de-Ioyasse et d'origine lyomnaise assuréce (pl. 24, n"3). Ce titulus a d'abord été lu MVR (ia) puis MVI. (sum) (I.iou, 1988) et publić ainsi (Desbat et al., 1987). Ia premic̀re lecture est aujourd'hui confirméc par un même litulus MVR (ia) découvert à Strasbourg (Baudoux, 1995, cat. ST. 178) sur une amphore de ce type dont l'origine lyonnaise a été confirméc par les analyses.

Mais ce sont surtout les amphores d'Augst qui fournissent la plus belle série de tituli picti, attestant que ces amphores étaient destinées à contenir des salaisons et notamment des sauces de poisson : une inscription désigne le garum et neuf autres la muria: Muria hisp (ana), Muria F́ (los) ou Muria Ant (ipolitanum), (fig. 32).

\section{LES AMPHORES DE TYPE 4}

Ies amphores de ce type présentes dans le matériel lyonnais n'ont pas livé d'inscription pouvant renseigner sur leur contenu. L'élément déterminant vient de l'amphore découverte à Strasbourg et d'origine lyomaise avérée. (On peut lire sur son col (pl. 26, n"2) une inscription dont la première ligne, SC: (ombri), apporte la preuve 


\section{CSETSE}
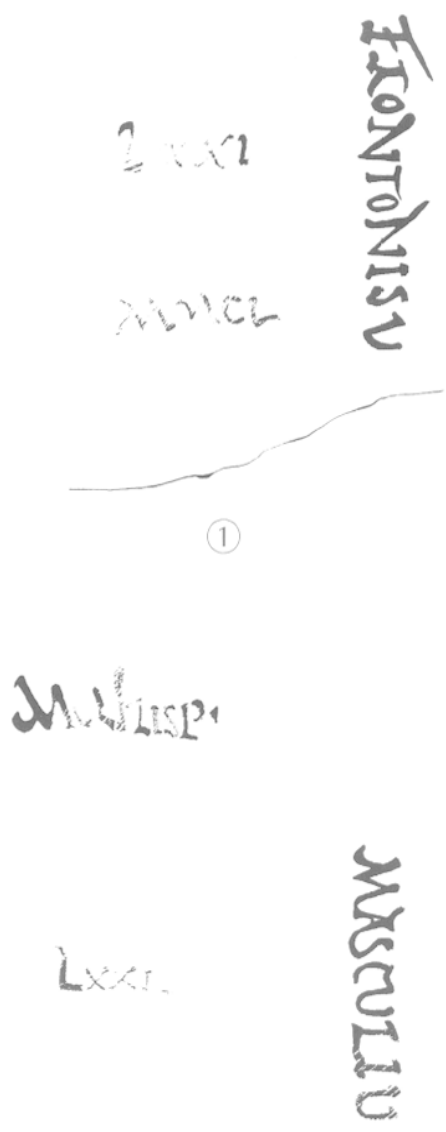

$N \cdot C 2$

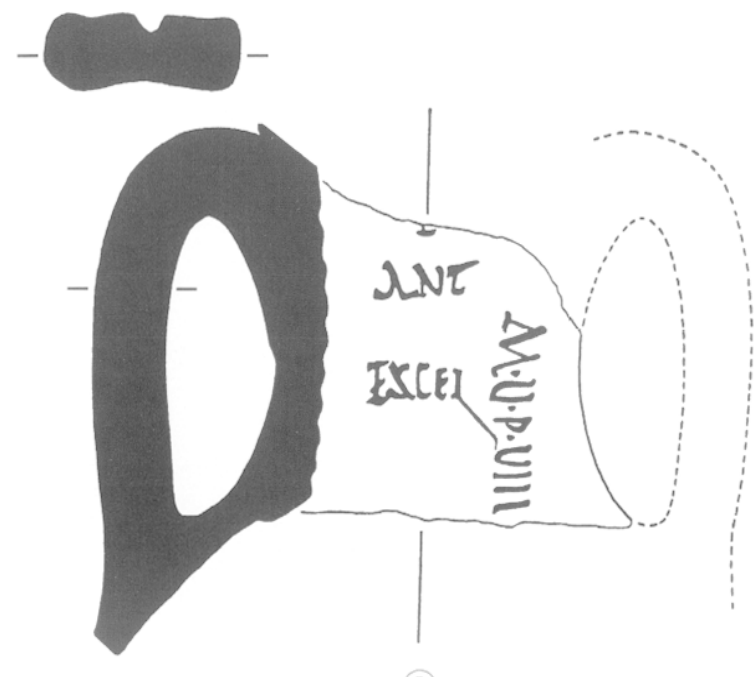

Fig. 32. Inscriptions peintes sur amphores de types 3 et 4 ditugst (d'après Martin-Kilcher; 1994a), (échelle : 1/2). d'un contenu (garum 引) de maquereau, lić aux produits de la pêche.

\section{L'ORIGINE DES CONTENUS}

Le problème se pose différemment selon le type d'amphore considéré. Pour l'amphore de type 4, la qualité du produit indiquée, garum (?) de maquereau, montre bien que c'est un produit de la pêche maritime dont il s'agit ici, et donc d'un produit importé.

I a question reste en revanche posée pour le contenu des amphores de types l et 2. Pour le vin, la proximité de la production allobroge invite à réfléchir sur les productions viticoles environnantes; quant aux sauces de poisson, un texte (Athenee, Deipnosophistes, 120, e) montre à lui seul que les produits de la pêche en eau douce ne peuvent être négligés.

\section{LE VIN}

Aucun élément n'est venu étaver l'hrpothèse d'une exportation d'un vin local au moyen des amphores de fabrication lyonnaise. On peut même voir, dans le fait que les amphores vinaires lyonnaises soient liées à la scule première génération, la preuve que cette production est sans rapport arec le vin allobroge qui, lui, continue d'exister.

Il y a done tout lieu de penser que le contenu des amphores vinaires de la production lyonnaise est importé et, au regard des types d'amphores fabriqués, une origine italique est plus que probable.

\section{LES SALAISONS}

Les indices d'une érentuclle production locale se révèlent, là aussi, inexistants. Rien n'est venu matérialiser le témoignage d'Athénée quant aux salaisons élaborées à partir des poissons d'eau douce. Ia solution au problème de l'approvisionnement en sel se heurte au silence des sources tant textuelles qu'archéologiques. Aucun vestige de construction ne permet de supposer la réalité d'une industrie de salaison à Lyon, ou à proximité, même si certaines traditions montrent qu'aujourd'hui encore le produit de la pêche peut être exploité ainsi. Reste l'ambiguïté des mentions Muria Hispana et Garum Hispamum. On retirera du silence des sources sur une éventuelle 
recette "à la mode espagnole " la possibilité de voir en ces tituli l'indication d'une rélle origine pour un produit mis en amphores à lyon et ainsi "étiqueté " afin de le distinguer d'autres productions comme celle d'Antibes par exemple.

\section{LA DIFFUSION DES AMPHORES I.YONNAISES}

\section{LES AMPHORES VINAIRES}

\section{LES AMPHORES DE TYPE 1}

En dehors d'un exemplaire d'Augst dont l'origine lyonnaise est possible, les Dressel 1 lyonnaises n'ont pas encore été identifiées sur les sites de consommation ${ }^{13}$.

\section{LES AMPHORES DE TYPE 2}

\section{Type 2A}

Cette variante n'a pas été rencontréc. Sa présence est toutcfois possible à Vienne où les fragments inventoriés (anses) ne permettent pas de trancher entre les deux sous-types.

\section{Type 2B}

I a présence de ce sous-type est attestéc par les analyses à Augst et peut-être à Vienne avec la réserve exposée ci-dessus. Cette présence est matérialisée à Augst par un col et un pied. Un pied de cette variante est également noté à Vidy-Iausanne; Stéphanie Martin-Kilcher (1990) le range dans la même séric que les amphores d'Augst. On a pareillement signalé des amphores sem-

13. I'échantillon se classe bien par ses constituants chimiques parmi les éléments lyonnais ; il possède cependant peu (ou pas ?) de rhyolite alors que les cing individus de lîlot 24 en sont riches. I.es caractéristiques typologiçues du fragment, ressiut interne de la levre, inclinaison externe et hauteur de cellect, diamètre d'embouchure, sont en revanche tout à fait semblables au matéricl lyonnais. Analyse chimique et comparaison typologique vont ainsi suffisamment dans le même sens pour admettre ici une origine lyomaise. blables à Besançon dans le matériel récolté lors de la fouille du grand parking de la mairie ${ }^{1 \cdot}$.

\section{LES AMPHORES À SALAISONS}

\section{LES AMPHORES DE TYPE 3}

Des amphores de type 3 présentes à Vidy-I ausanne et Viemne ont une origine lyonnaise prouvé par les analyses ${ }^{15}$. On ne peut toutefois trancher quant à leur appartenance à l'unc ou l'autre des deux variantes.

\section{La variante $3 \mathrm{~A}$}

I.es analyses ont permis d'attribuer une origine lyonnaise à des amphores recueillies à Angers (pl. 22, n $n^{m} 7$ et 8), Augst (pl. 22, n"3 et 4), Brumath et Strasbourg ${ }^{16}$ (fig. 22, n"11). I ces amphores de ces deux derniers sites sont classées à l'intérieur d'une série homogène fondée sur l'aspect visucl de la pâte (Baudoux, 1995). On peut donc considérer comme certaine la présence d'amphores lyonnaises de cette variante sur les sites concernés par cette série : Biesheim, Beblenheim, Metz, Scarponne et Thionville (pl. 22, n"12).

\section{La variante $3 B$}

Comme pour la variante précédente, les analyses certifient sa présence à Angers (pl. 24, n”6), Augst (pl. 24, n" 10 et 11 ) et Strasbourg (pl. 24, n"14). Des exemplaires découverts à Grenoble (pl. 24, n'15) et surtout Autun (pl. 24, n“ 7 à 9, 12 et 13) font ajouter ces localités à la liste des sites où cette variante est attestéc par les analyses ${ }^{17}$.

\section{LES AMPHORES DE TYPE 4}

L'inventaire de ces amphores de petit module confirme l'existence de deux sous-types $4 \mathrm{~A}$ et $4 \mathrm{~B}$ ( $f$. supra, typologic).

14. Ie matériel n a pu être examiné dans le détail ni faire lobjet d'analyse's.

15. Réf. analyses pour Vidy-l ausanne : AMT 732 e 734 ; pour Vienne (fouille de Saint-Romain-en-(Bal) : AMT 675, AMT 676 et AMT 8.51. 16. Réf. analveses pour Angers : AMT 940 (1 AMT 941 ; pour Augst : A.VT 585 a AMT 779 ; pour Brumath : A.MT 933 ; pour Strasbourg : A.MT 918 ( AMT 921.

17. Réf. analyses pour Angers : AMT 938 ; pour Augst : AMT 86.3 ("1 864 ; pour Autun : AMT 911, 912, 913, 914, 915, 916 et 917: pour Girenoble: : AMT 924 ; pour Strasbourg : A.MT 922. 
C'est ainsi que les deux amphores rangées par les analyses dans le groupe lyonnais présentent, pour l'une découverte à Strasbourg, une lèvre en bourrelet et, pour l'autre recucillie à Augst, une lèvre en amande.

Les deux sous-types sc rencontrent dans l'est de la France à Biesheim et Metz. Elles possèdent une pâtc qui les rangent dans la même série que les amphores de type $3 \mathrm{~A}$ d'origine lyonnaise attestée (cf. ci-dessus). On accordera également une probable origine lyonnaise à des amphores découvertes à Besançon ( $f$. note 17) et à Roanne.

En l'état actuel de la recherche, les cartes de répartition des amphores lyonnaises laissent percevoir une diffusion essentiellement tournée vers le nord et dans une moindre mesure vers l'ouest (fig. 33).

En Narbonnaise, sur l'axe rhodanien, la présence de la production lyonnaise n'est plus assuréc au-delà de Vienne. C'est là le dernier site où des amphores vinaires et à salaisons d'origine lyonnaise attestée par les analyses sont répertorićes. À Valence déjà le faciès change : seul un exemplaire de type 3B peut être proposé comme étant lyonnais par comparaison typologique. Plus au sud, les amphores lyonnaises sont totalement absentes. On ne les rencontre ni à Orange ${ }^{18}$ ni à Fos-sur-Mer (Liou, Sciallano, 1989) ni même dans l'une des 19 épaves de Méditerranée susceptibles d'en contenir ${ }^{19}$.

Les amphores lyonnaises sont également absentes d'un sud-ouest en contact avec l'itinéraire rhodanien par la voie domitienne. Elles ne figurent pas en tout cas dans les collections rassemblées à Toulouse (Vidal, s.d.) et dans l'inventaire du matériel amphorique mis au jour à Ambrussum (Laubenheimer, 1989).

Elles ont en revanche laissé quelques traces sur les itinéraires qui, depuis Vienne, mènent à l'Italie du Nord. Mais ces traces sont ténues : un exemplaire

18. Fouille du Mas des Thermes. I. mobilier amphorique est inédit; nous remercions Patrick Thollard de nous en avoir autorisé la consultation.

19. Quatre des quinze épaves étudiées dans le cadre de la recherche sur les amphores vinaires (Dangréaux, à paraître) contenaient également des amphores de type Dressel 9 ou Dressel $7 / 11$ : Balise de Rabiou, le Brusc, Planier 5 et Chrétienne H. Trois s'ajoutent à la liste pour ce qui concerne ces derniers types d'amphores : Chrétienne B (Benoit, 1956), Deux Frères (Tchernia, 1969) et Chrétienne I (Pomey et al., 1988). À l'exception de l'épare (Chrétienne I, le matériel a pu faire l'objet de comparaison typologique suffisante pour écarter une éventuelle origine lyonnaise. (inćdit) de type 3B d'origine lyonnaise attestée par les analyses à (Grenoble, deux exemplaires attribués par la typologie aux types 3A et 3B pour l'ensemble du mobilier amphorique conscrvé au musée d'Aoste (Rougier, 1988).

L'Aquitaine semble totalement exclue de la diffusion des amphores lyonnaises. En l'un des points d'aboutissement de l'itinéraire, I ibourne, les découvertes locales anciennes ou récentes présentes au muséc de la ville n'ont livré aucun individu pouvant faire suspecter une diffusion vers cette région (Berthault, Watier, 1988).

À l'examen des cartes de diffusion, deux directions paraissent donc essentiellement concernées : vers l'ouest par la vallée de la Loire et surtout vers le Rhin. L'examen de la diffusion en direction du Rhin invite toutefois à compter non pas trois mais deux voies de circulation reliant Lyon et le Rhin. Dès l'époque augustéenne les axes longeant Saône et Moselle d'une part, Rhône et Aar d'autre part, seraient utilisés (on y retrouve des amphores produites à Lyon autour du changement d'ère). Tout laisse à croire par contre que la voic du Doubs, quoique utilisée pour alimenter les localités rencontrées sur son cours, ne servit pas de véhicule aux matières pondéreuses à destination du Rhin.

L’importance accordée au cheminement fluvial sert une telle interprétation. Vers l'est et le nord-est, le circuit de distribution des amphores lyonnaises sous Auguste reposerait ainsi sur deux axes menant à des camps militaires (Windisch et Trèves-Pétrisberg) et par cux aux localités de la région rhénane ${ }^{20}$. On peut donc nuancer ici le jugement porté jusqu'alors (Desbat, Martin-Kilcher, 1989) quant à l'utilisation concomitante à l'époque d'Auguste des trois itinéraires.

Vers l'ouest, pour le portage reliant l'axe RhôncSaône à la Loire, deux itinéraires on été proposés. Pendant longtemps, l'hypothèse d'une liaison IyonRoanne par la montagne de Tarrare a prévalu (Bonnard, 1913, p. 101). J. Rougé (1974), s'appuyant sur l'association des nautes de la Loire avec ceux de la Saône dans la même mention épigraphique (CIL, XIII, 1709), lui a préféré une jonction via Chalon-sur-Sâone, la dépression de la Bourbince et Digoin.

20. Parmi celles-ci, c'est Augst qui pour l'heure parait la mieux approvisionnée (Martin-Kilcher, 1994a). 


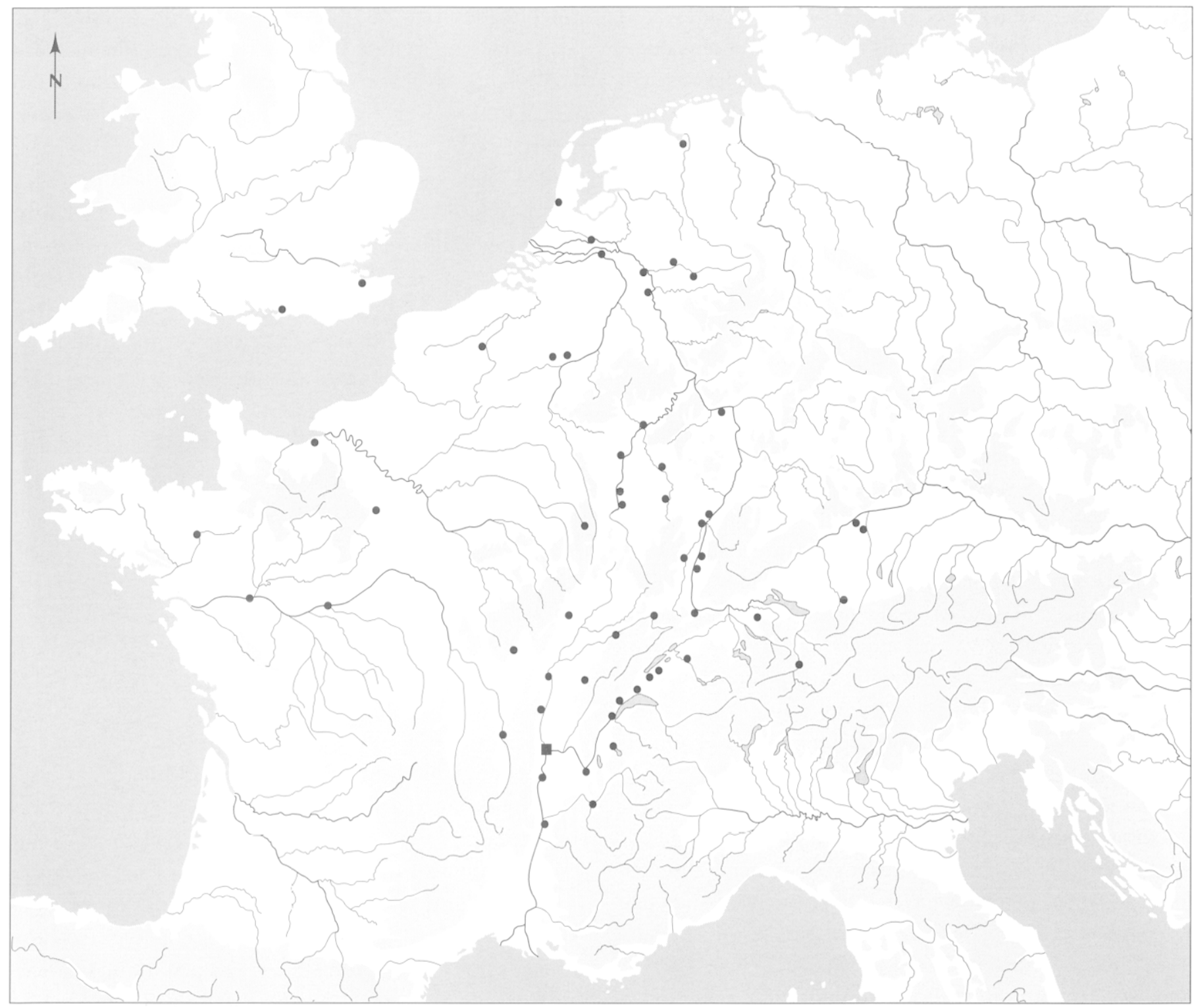

Fig. 33. Carle de diffusion des amphores de type lyonnais.

Il reste difficile de trancher entre ces deux propositions. Il est fort possible de voir un changement s'effectuer aree le temps. Roanne, sur l'ancienne voie qui de Vienne reliait le Rhone à la Loire par Feurs (Pelletier, 1982, p. (62), a pu servir de jalon dans un premier temps : une amphore de type $3 \Lambda$ y a été découverte. Digoin prendrait ensuite le relais au fur et à mesure que s'affirment les corporations de batelleries, mautes sur la loire (CIIL, XIII, 1709, 3105 el 3114), utriculaires sur l'Arroux (CII, XIII, 2839). ("̈est par ces dernicrs qu'Autun serait alors alimentée : les amphores de la seconde génćration (type 3B) y sont relativement nombreuses.
Ce schéma présente l'arantage d'expliquer pourquoi Roanne et Autun sont approvisionnées en amphores lyomnaises alors qu'clles marquent la limite de leur diffusion vers le Sud-Ouest et la Manche : c'est en fait au réscau ligérien qu'il conviendrait de les rattacher. Ce que l'on proposera à la vérification des découvertes à venir.

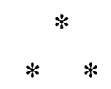

I a production d'amphores à Lyon commence dans le dernier quart du I" s. avant J-C. On note l'absence d'amphore de type Iyon sur les sites comme Dangstetten 
(Fingerlin, 1986) ou Oberaden. À l'inverse le type 3A est attesté à Haltern (Asskamp et al., 1989, abb. 152) ${ }^{21}$. On peut penser que la diffusion des amphores a suivi les mêmes circuits commerciaux que la sigillée et les parois fines.

La diffusion des amphores de type $3 \mathrm{~A}$ et $3 \mathrm{~B}$ courre une large zone à partir de Iyon (fig. 33). Un grand nombre de découvertes ont été identifiées sur la base des publications, en particulier le long de la vallée du Rhin, mais la diffusion s'est aussi effectuée en direction dc l'ouest, par les vallées de l'Allier et de la Loire, comme le montrent les découvertes d'Angers (Siraudeau, 1988). Il cst probable que la diffusion a été moindre dans l'ouest, mais il est clair également que la faiblesse des études amphoriques sur le matériel des régions du Centre et de l'Ouest minorisent très certainement leur présence.

Sur les rares sites pour lesquels nous disposons de données quantitatives les amphores gauloises à saumures représentent un pourcentage élevé :

À Autun (Olmer, 1994), $3 \%$ du total mais $21 \%$ des amphores à saumures.

À Braives (Brulet et al., 1992), les Dressel 9 similis représentent $3 \%$ du total mais $30 \%$ des amphores à sautmures.

À Augst (Martin-Kilcher, 1994a), $14 \%$ du total mais $50 \%$ des amphores à saumures.

Dans l'est de la (xaule (Baudoux, 1995), $18 \%$ sur toute la période.

À Besançon (Guilhot et al., 1992), seulement 1,05\% du nombre total d'amphores. Toutefois ce faible résultat est dû en grande partie à la grande quantité de Dressel 1 qui représentent $42 \%$ du total des amphores et encore près de $20 \%$ dans les contextes de la fin du II*s. Ln comptage par période, en éliminant le matériel résiduel rendrait mieux compte de leur place réclle.

Il n'est pas possible d'évaluer avec certitude la part de la production lyonnaise dans ces amphores et, sur certains sites, comme Augst, ces chiffres prennent en compte d'autres types d'amphores gauloises comme l'amphore de Fréjus type I.enzburg (Augst 33) ou les types Augst 34, 35 et 36, voire les Dressel 16. Toutefois ces différents types d'amphores ne représentent qu'un faible pourcentage des amphores à saumures gauloises (40 individus à Augst sur 504) et bien que l'on puisse

21. Une amphore complète est classée dans te type Ha 71 et donnée comme Olamphore (sic). supposer d'autres atcliers que ceux de Lyon même, en particulier à Vienne, il ne fait pas de doute que les amphores produites à Lyon constituent la majorité des amphores à saumures gauloises recueillies sur les sites de consommation.

Il est à noter que ce sont les types correspondant aux amphores à saumures qui connaissent la plus grande durée de production et la plus grande diffusion. Dans l'état actuel de nos connaissances, la production des amphores vinaires lyonnaises semble limitée à la période augustéenne et aux premières décennies de notre ère. On peut s'interroger sur la disparition rapide des amphores vinaires. Si l'on admet que celles-ci étaient bien destincés au transvasement de vins arrivant en vrac à Lyon, il faut expliquer pourquoi leur production cesse plus tôt que celle des amphores à saumures. Il faut supposer soit que le vin est commercialisé en tonneau jusque sur les lieux de consommation, soit que le transvasement ne s'opère plus à Lyon mais en d'autres lieux et dans d'autres types d'amphores. Peut-ĉtre une partie de la production des amphores de Gaule méridionale était-elle destinée à cet usage? On peut aussi conjecturer que le souci d'économie ait conduit les négociants à préférer l'acheminement du vin en tonneaux sur une plus grande partic du parcours et que le transvasement s'effectuait aux points de rupture de charge ou dans les centres de redistribution. Ce phénomène expliquerait la multiplication des sites producteurs d'amphores durant le $\mathrm{I}^{\mathrm{ct}} \mathrm{s}$., sans qu'il s'agisse forcément de l'indice d'une production de vin locale, contrairement à l'idée souvent défendue. En l'absence d'autres indices plus probants, comme la découverte de pressoirs, la production d'amphores, comme celle de Gueugnon, n'est pas la preuve d'une production vinicole dès le $\mathrm{I}^{\mathrm{er}} \mathrm{s}$. De même la production de Dressel 2/4 à Augst, interprétée comme l'indice d'une production de vin, est plus probablement liée à des transvasements pour la redistribution. (Martin-Kilcher et al., 1987).

Il reste à expliquer pourquoi le même phénomène ne s'est pas produit pour les amphores à saumures et pourquoi leur production s'est maintenuc. Faut-il supposer une chaîne de distribution différente de celle du vin ? En particulier un contrôle du marché avec l'Espagne par des "diffusores " installés à lyon?

À partir du II's. le problème se pose également pour les amphores à saumures, puisque celles-ci disparaissent à leur tour. On ne peut pourtant en conclure que l'impor- 
tation et la diffusion des satumures cessent pour autant. L'épigraphic nous le confirme avec le tombeau de Marcus Primius Secundianus, batelier du Rhône et "negotiator muriarii ", daté du II" ou du III" s. Il faut donc envisager que la commercialisation des sauces de poisson utilise d'autres conteneurs que les types d'amphores connus. Il est possible que de nouveaux types de récipients aient été utilisés à cette fin, en particulier des vases de petite taille. On connaît en effet des types particuliers de cruches qui peuvent avoir servi à cet usage, attesté par une inscription peinte (fig. 34).

La carte de répartition des amphores lyonnaises se superpose pratiquement à celle des sigillées lyonnaises, bien que couvrant une période plus large. Il est probable que la production s'est poursuivie au II's., mais les témuins livrés par les sites de production semblent s'interrompre à la fin du I" s. La fabrication des amphores couvre une période d'un siècle au moins. Mais celle des amphores vinaires est vite abandonnée alors que celle des amphores à saumures, plus importante à partir de la seconde moitić du I"r s., connaît une diffusion plus large.

Il est clair que les amphores lyonnaises n'étaient pas destinées à contenir des produits locaux mais étaient destinées au transwasement de produits importés en rac dans d'autres contencurs (dolia, tonneaux, voire outres). La découverte d'entrepôts à dolia sur le quai des Étroits ainsi peutêtre que sur le site de la Butte ou place Bellecour, ainsi que la fabrication de poix à lyon fournissent autant d'éléments qui confortent cette hypothèse. I.e bouchon de tonneau recueilli dans la Saône avec la marque VRITTI, constitue un indice pour l'arrivée à Lyon de saumures de Bétique mises en

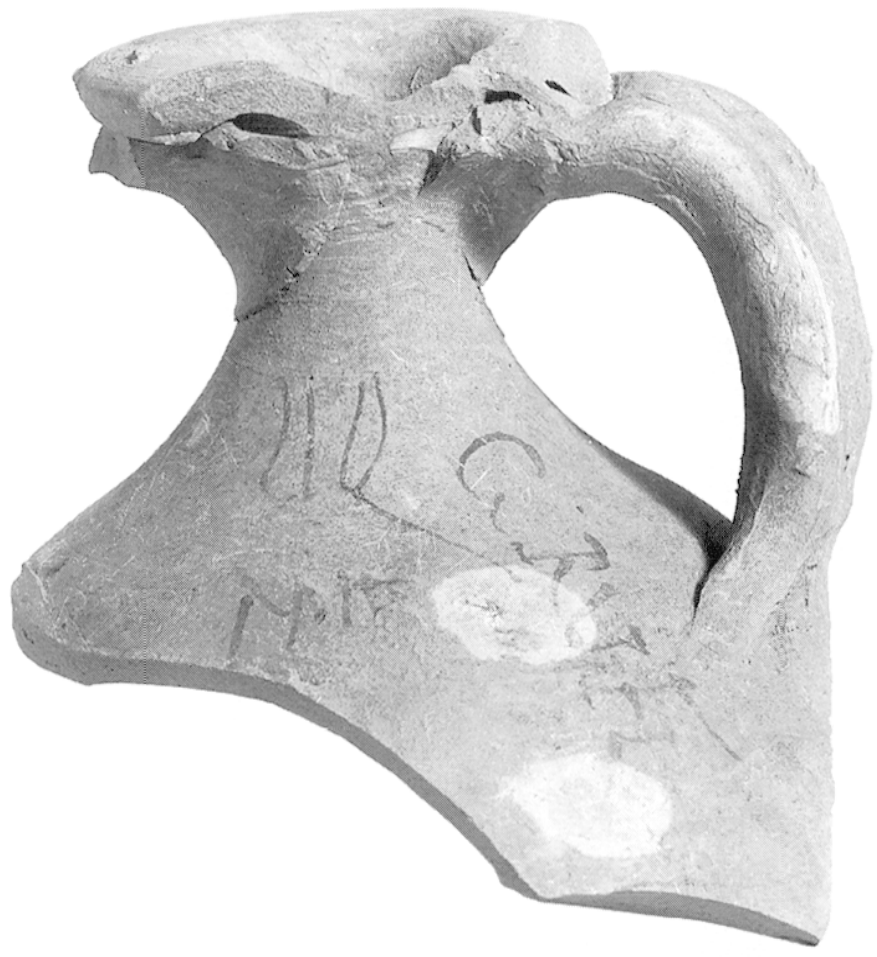

Fig. 34. Amphorefle arvec titulus liq(uanem), (photo (ientre Camille Jullian).

amphores sur place. De même la production du type Dressel 16 ou le col d'Augst avec l'inscription antipolitanum semblent indiquer que certains produits du sud de la Gaule ćtaient également transvasés à Lyon (fig. 32, n"3).

La présence à Lyon de grands négociants, nautes du Rhône et de la Saône, dont certains commercialisaient plusieurs produits, facilitait une telle organisation. 


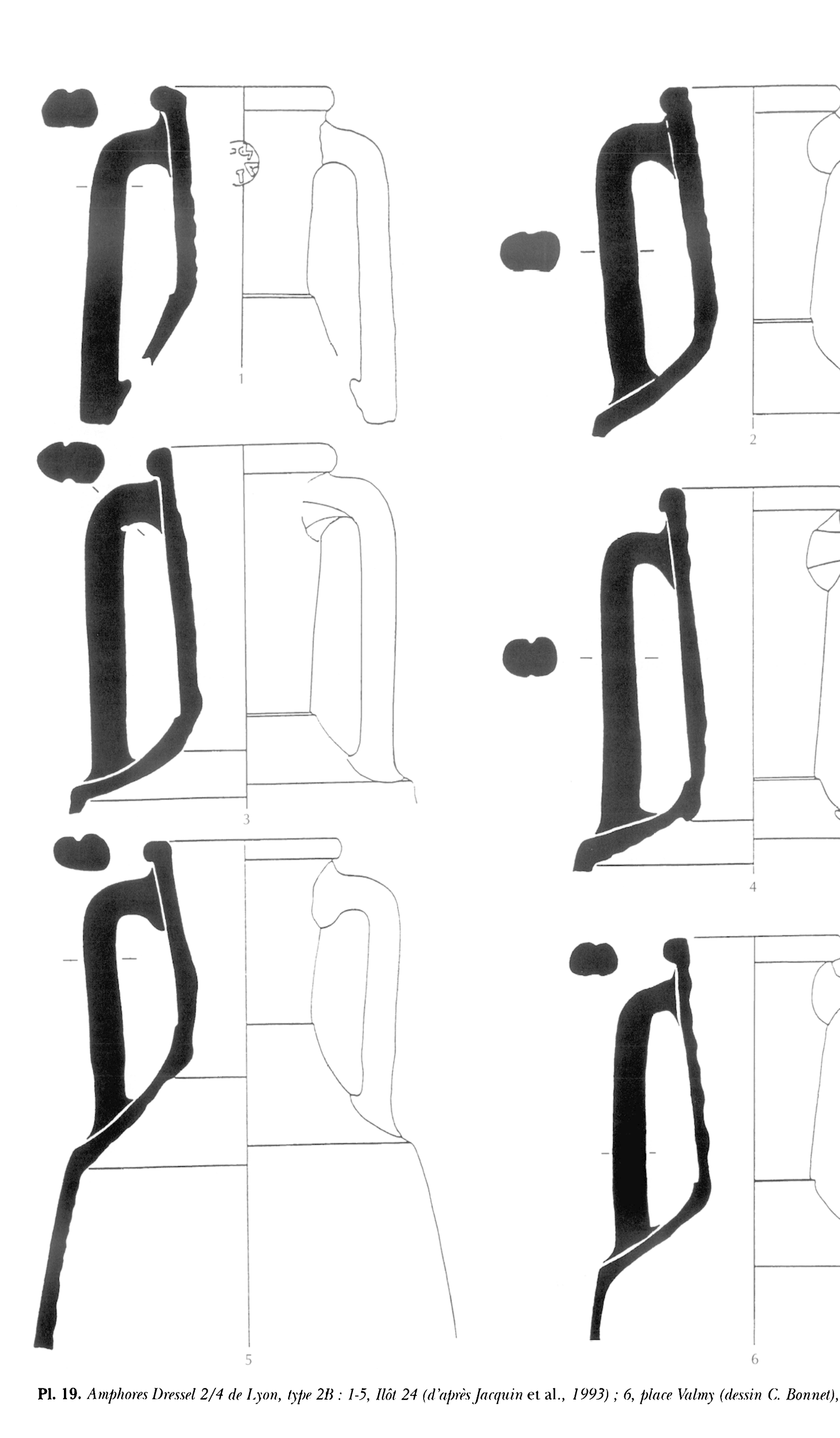



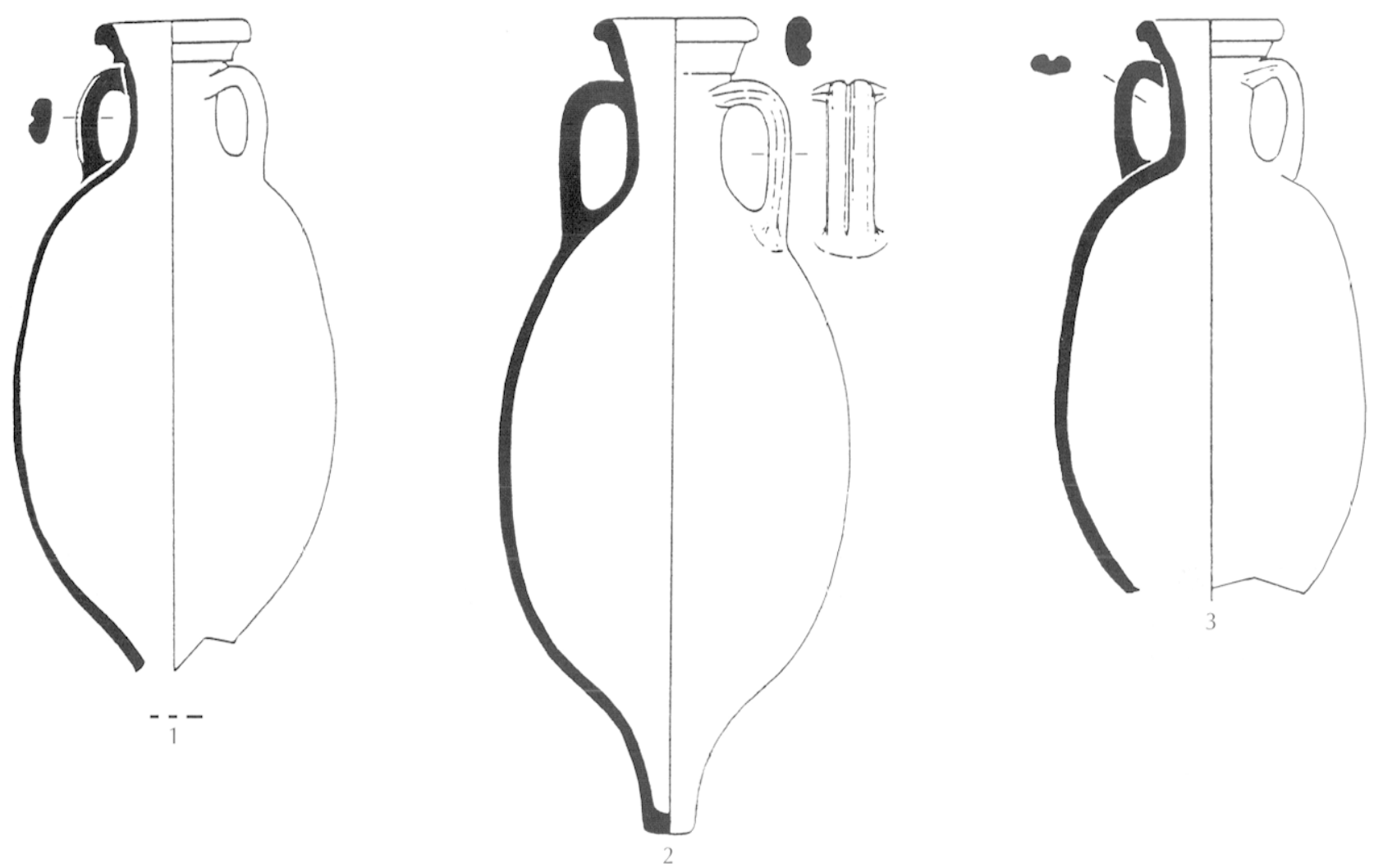

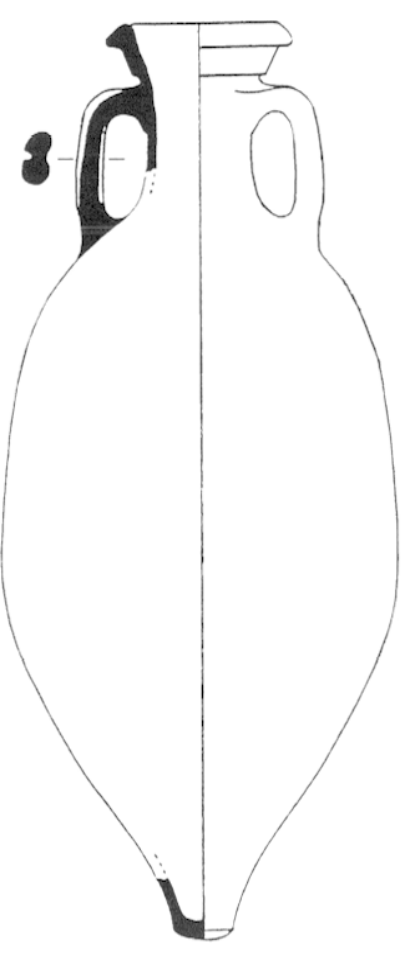

4

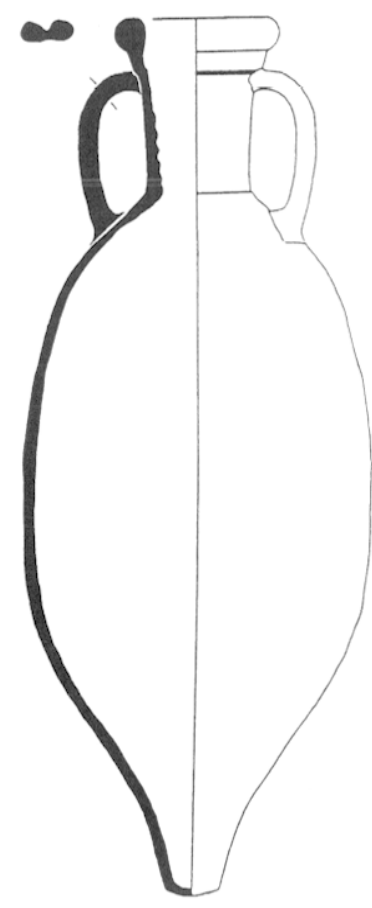

5

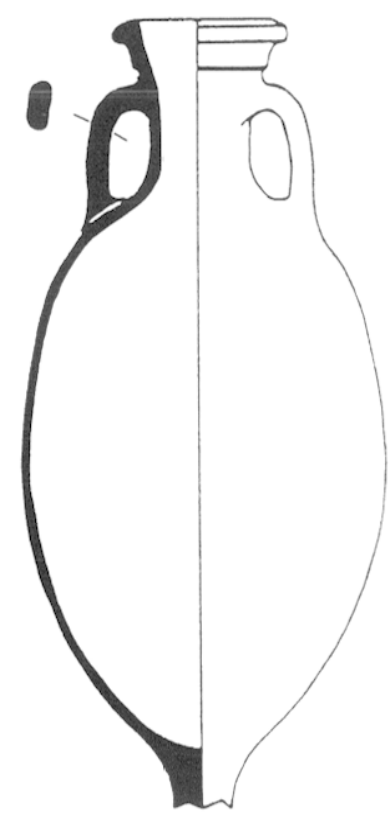

6

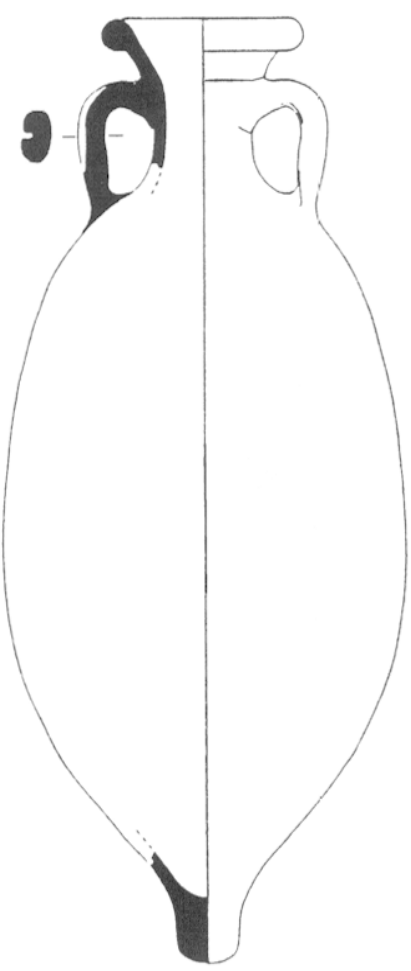

7

Pl. 20. Amphores de type 3A : 1, 3, 6, Lyom, la Fanorite (Becker et al., 1986); 2, Kempten (Mackensen, 1978) ; 4, 7, Lyon, fonds ancien du Musée de la (ïzilisation gallo-romaine (I)angréaux et al., 1992); 5, I.yon, place Valmy (dessin (:. Bonnet), (échelle : 1/10). 

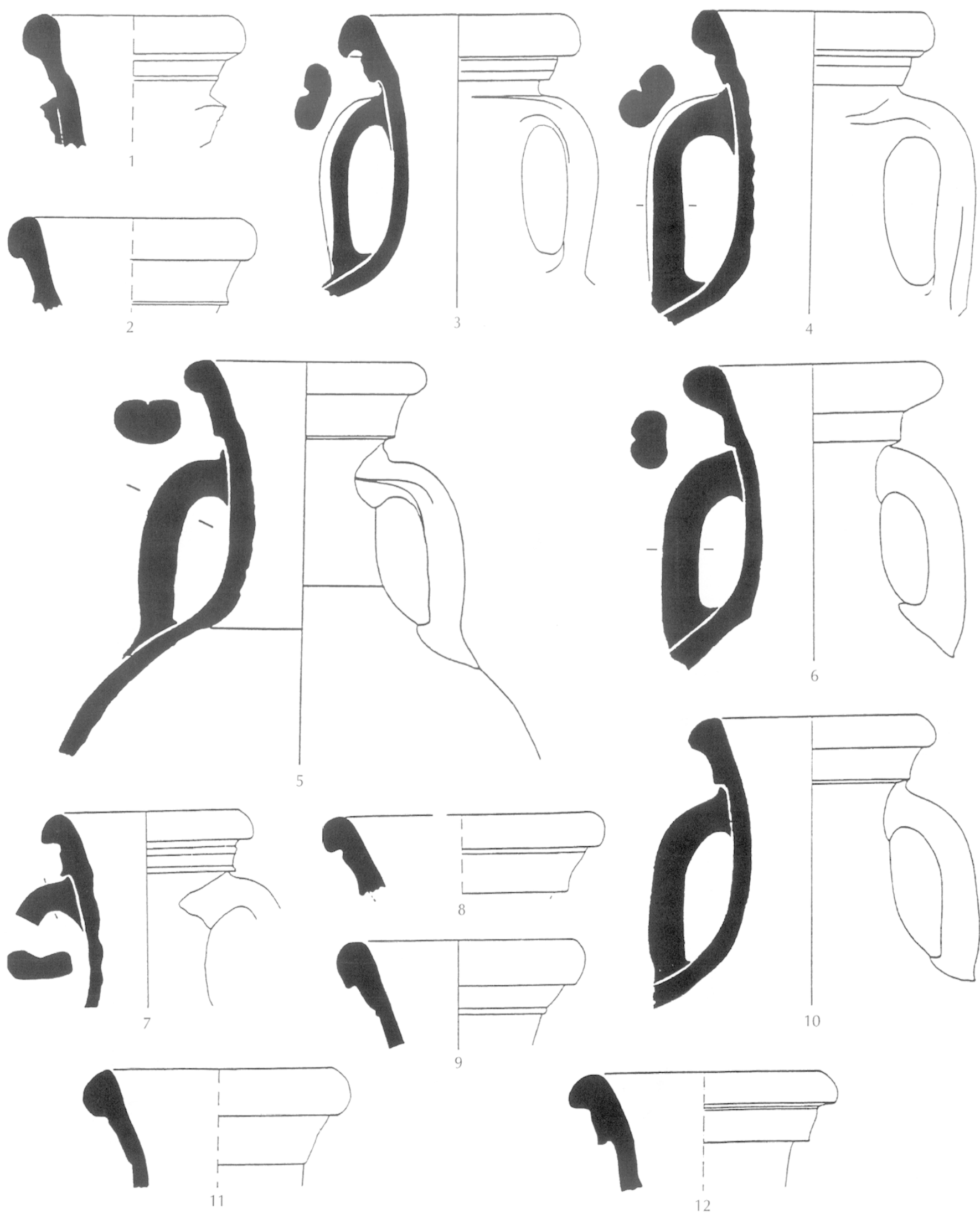

Pl. 21. Amphores de Lyon, type 3A : 1, 2, 8, atelier de la Manutention ; 3, 4, 11, 12, atelier de la Muette; 5, 6, 10, Ilôt 24 (Jacquin et al., 1993) ; 7, 9, place Valmy (dessin (: Bonnet), (échelle : 1/4). 


$$
\begin{array}{ccc}
1 & 1 & 1 \\
j & d & 1 \\
d & 1 & 1 \\
j & -4 & -j
\end{array}
$$



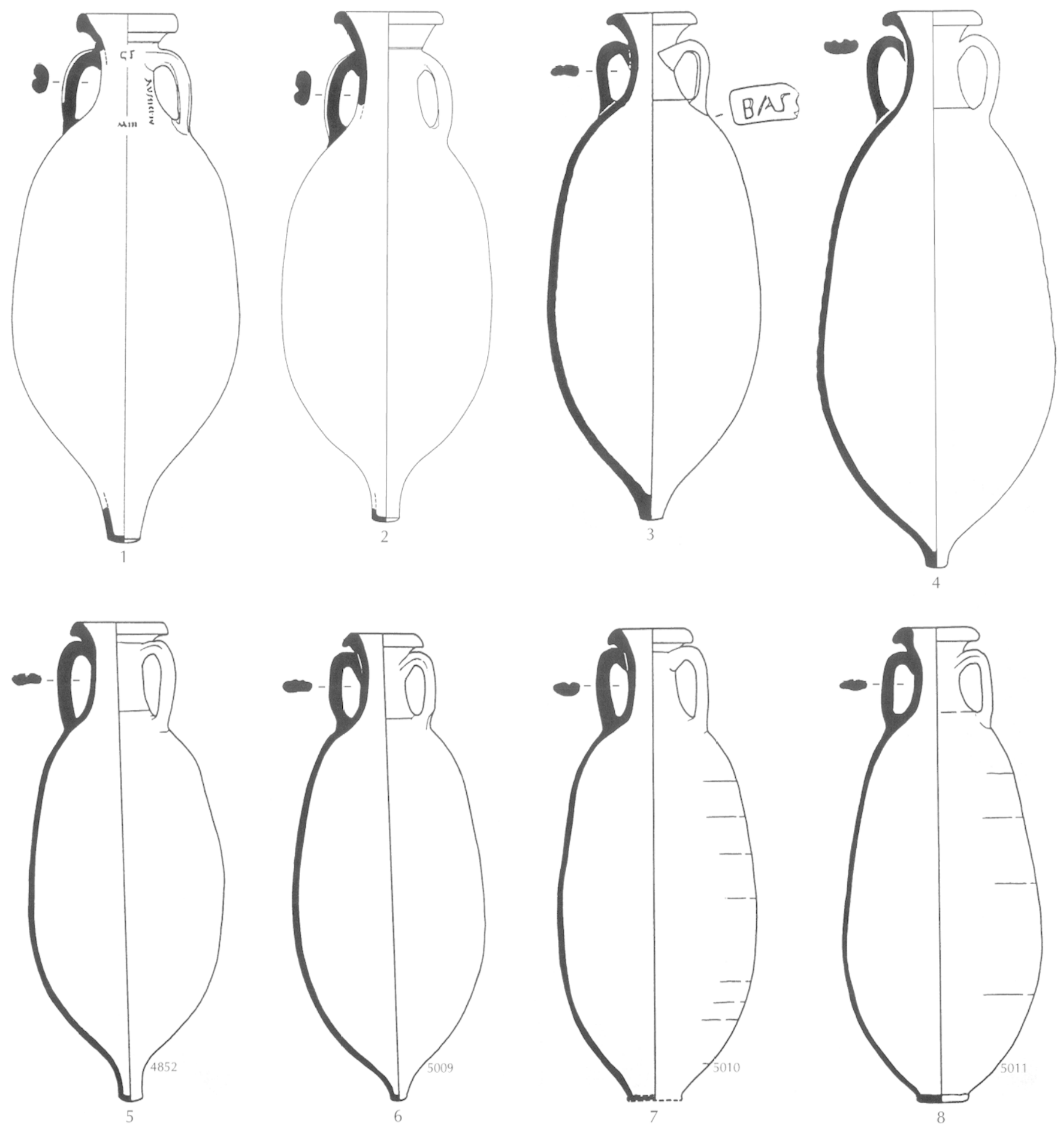

Pl. 23. Amphores de type 3B:1, Lyon, nue des Farges ; 2, Lyon, fonds ancien du Musée de la Cizilisation gallo-romaine; 3, Cenèze (Paunier, 1981); 4, Nimègues (Stuart, 1977) ; 5-8, Augst (Martin-Kilcher, 1994a et b), (échelle: 1/10). 

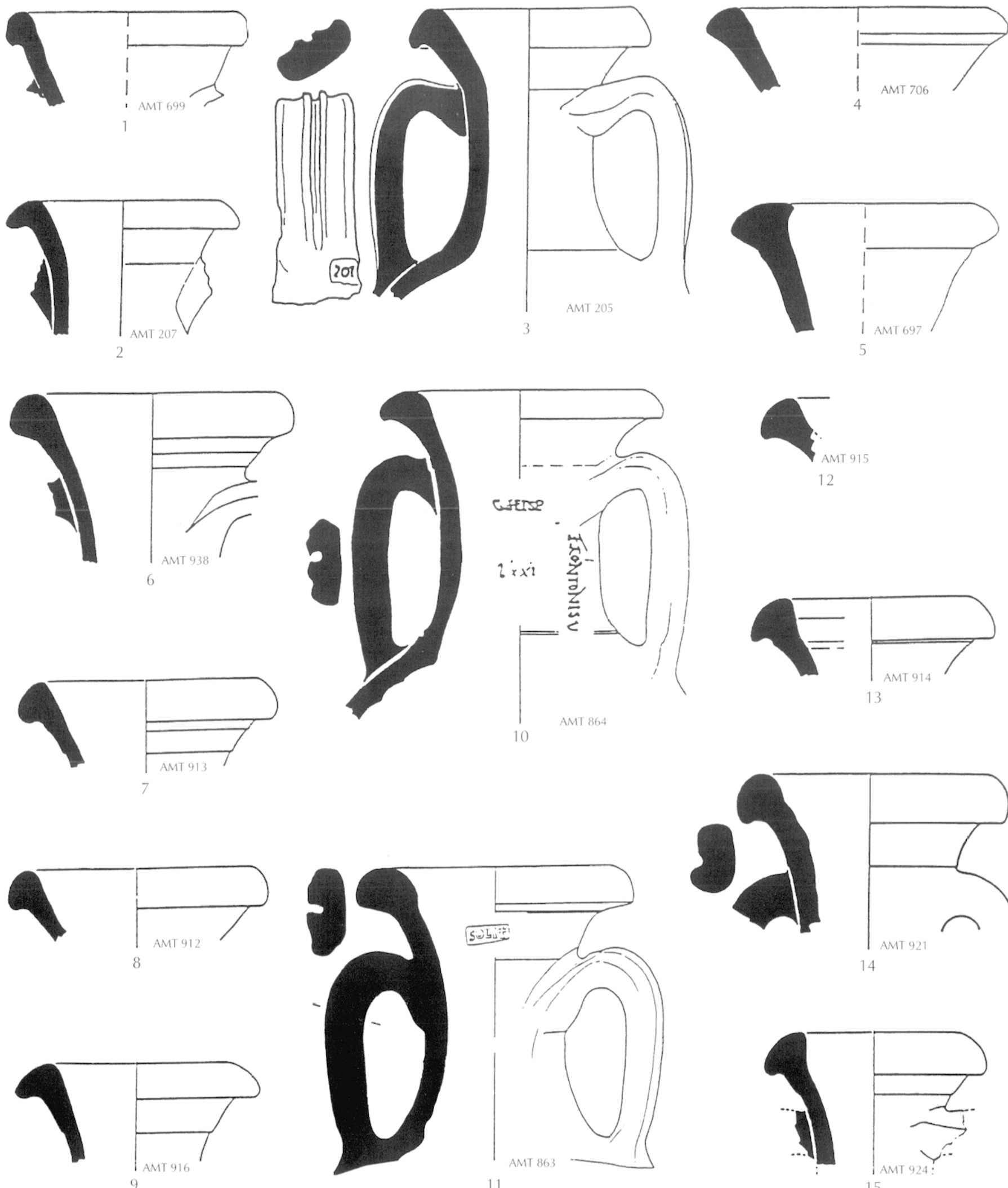

11

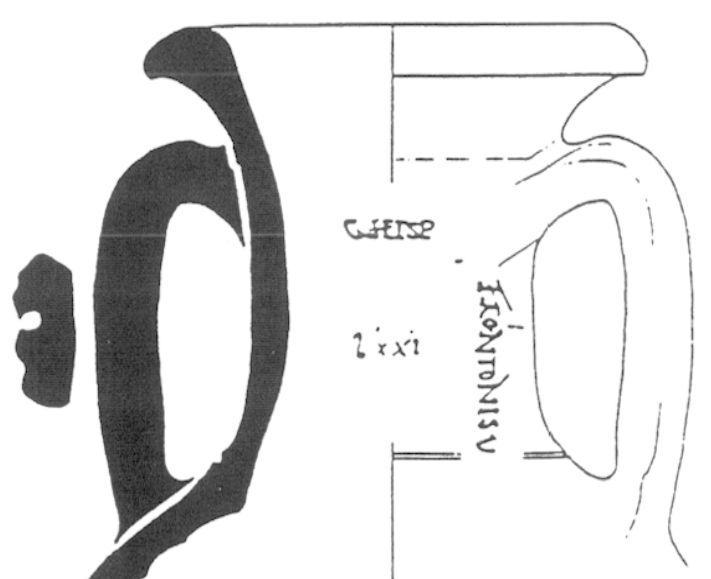

AMT 864

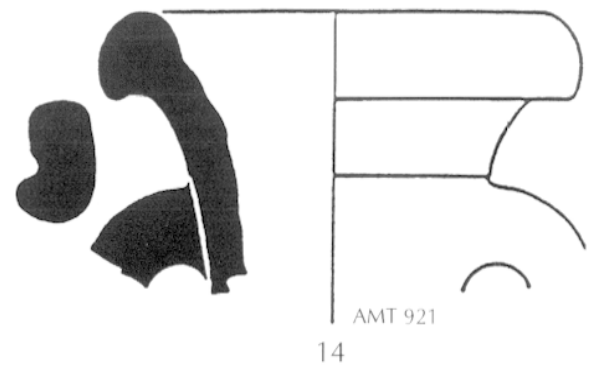

Pl. 24. Amphores de type 3B. 1-5, I.yon : 1, 4, atelier de la Manutention ; 2, 3, Bas-de-Loyasse ; 5 , atelier de la Muetle ; 6-18, divers sites de consommation: 6, Angers; 7-9, 12, 13, Aulun; 10, 11, Augst; 14, Strasbourg; 15, (Grenoble (échelle: 1/4). 

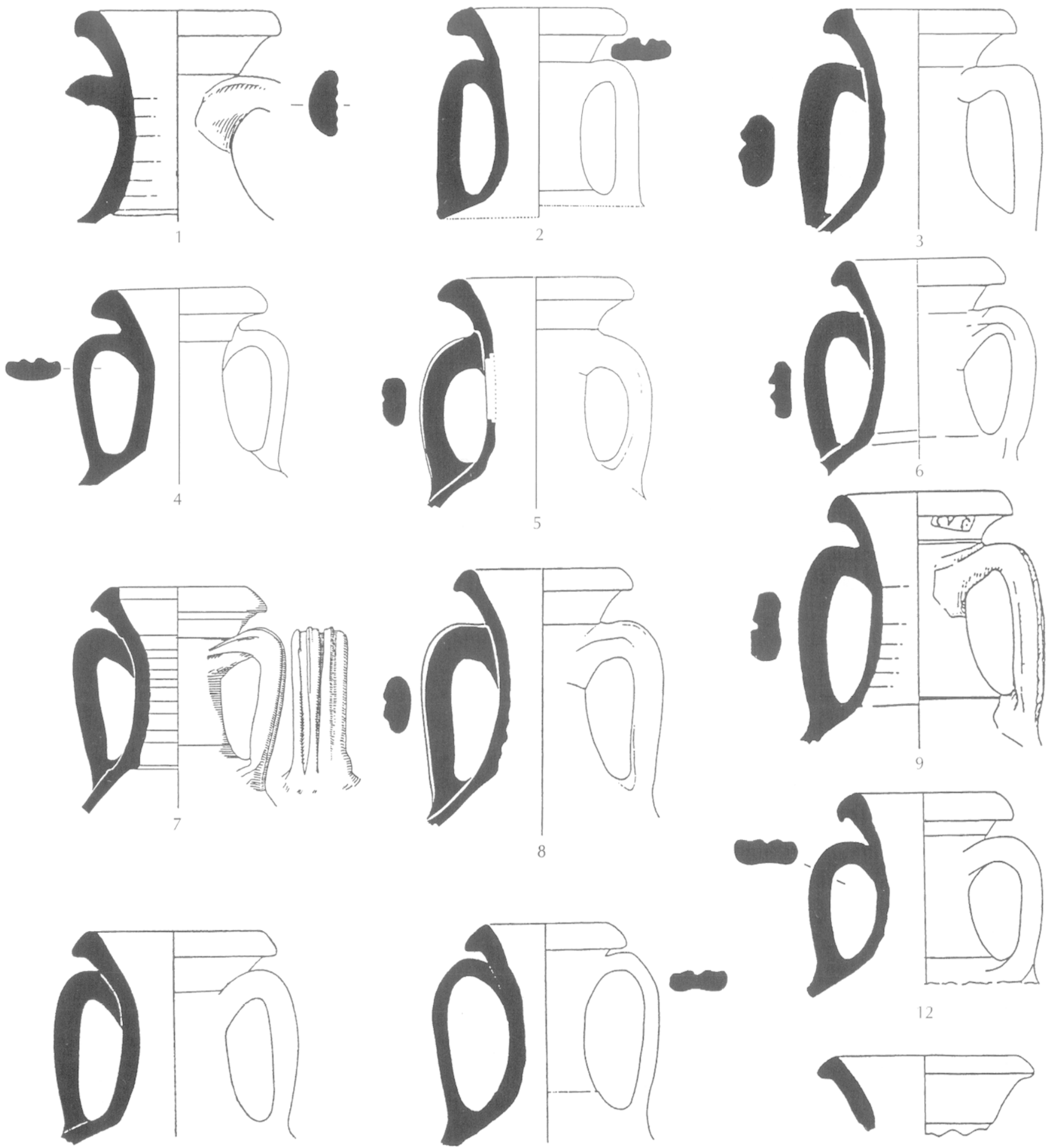

10

11

13

Pl. 25. Amphores de 1ype 3B: 1, Neuss (Filizinge); 1972); 2, Strasbourg-Komigshoffen (Baudoux; 1995); 3, Aislingen (Llbert, 1959); 4, Riegel

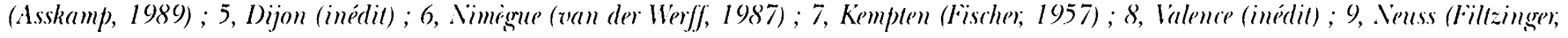
1972) ; 10, Aremtsburg (Holuerda, 1923) ; 11, Fishbourne (Cunliffe, 1971) ; 12, Lenzhurg (Ettlinger; 1978) ; 13, Mayence (Banlz, 1962), (échelle : $1 / 6)$. 

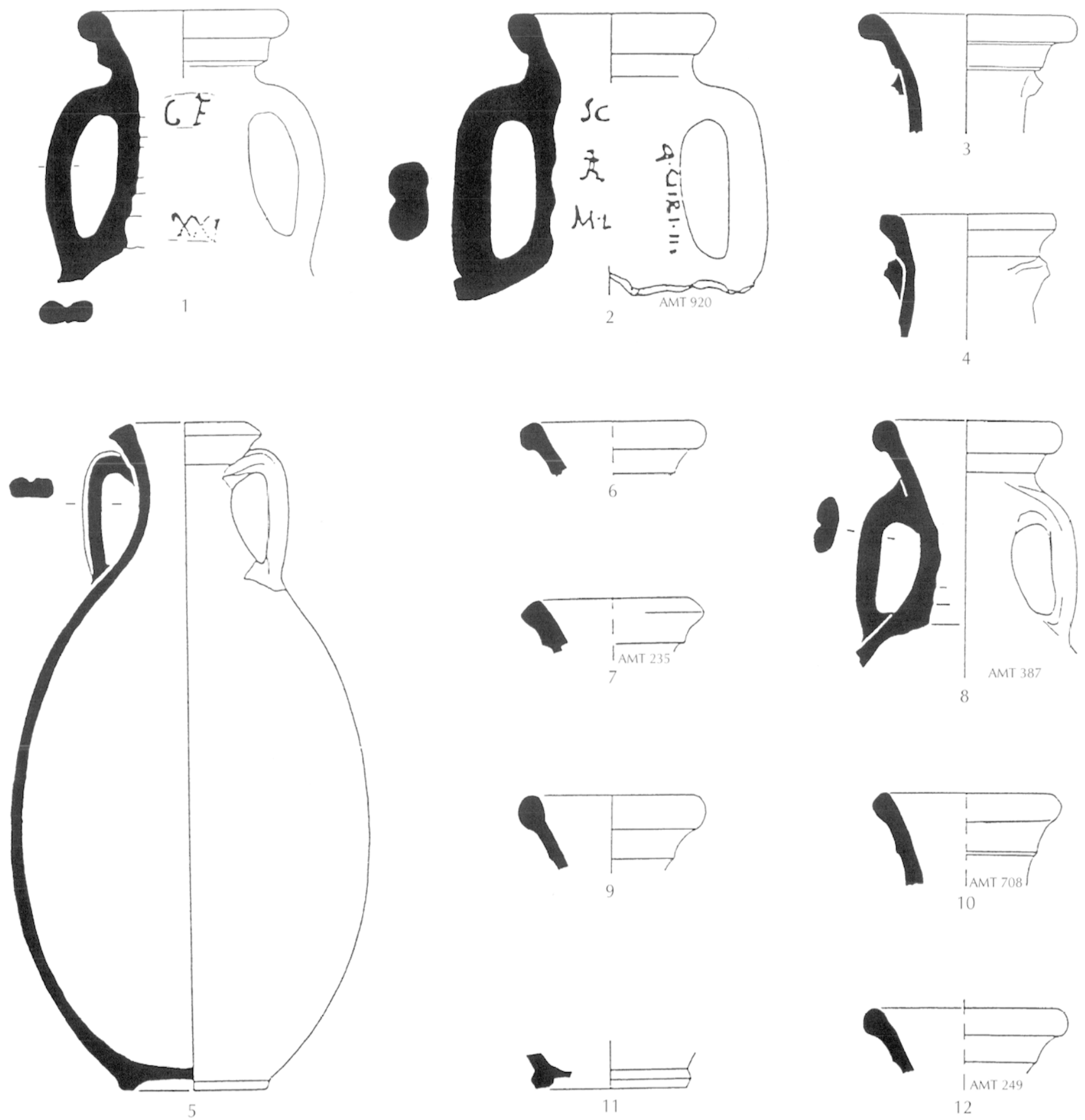

Pl. 26. Amphores de type 4A:I, Augst; 2, Strasbourg ; 3, Lyon, rue Chambonnet ; 4, Saint-Romain-en-Gal ; 5, musie de Vienne ; 6, L.yon, alelier de la Mamutention; 7-10, 12, I.yon, Bas-de-Loygasse; 11, L.yon, place Valmy (échelle 1/4). 

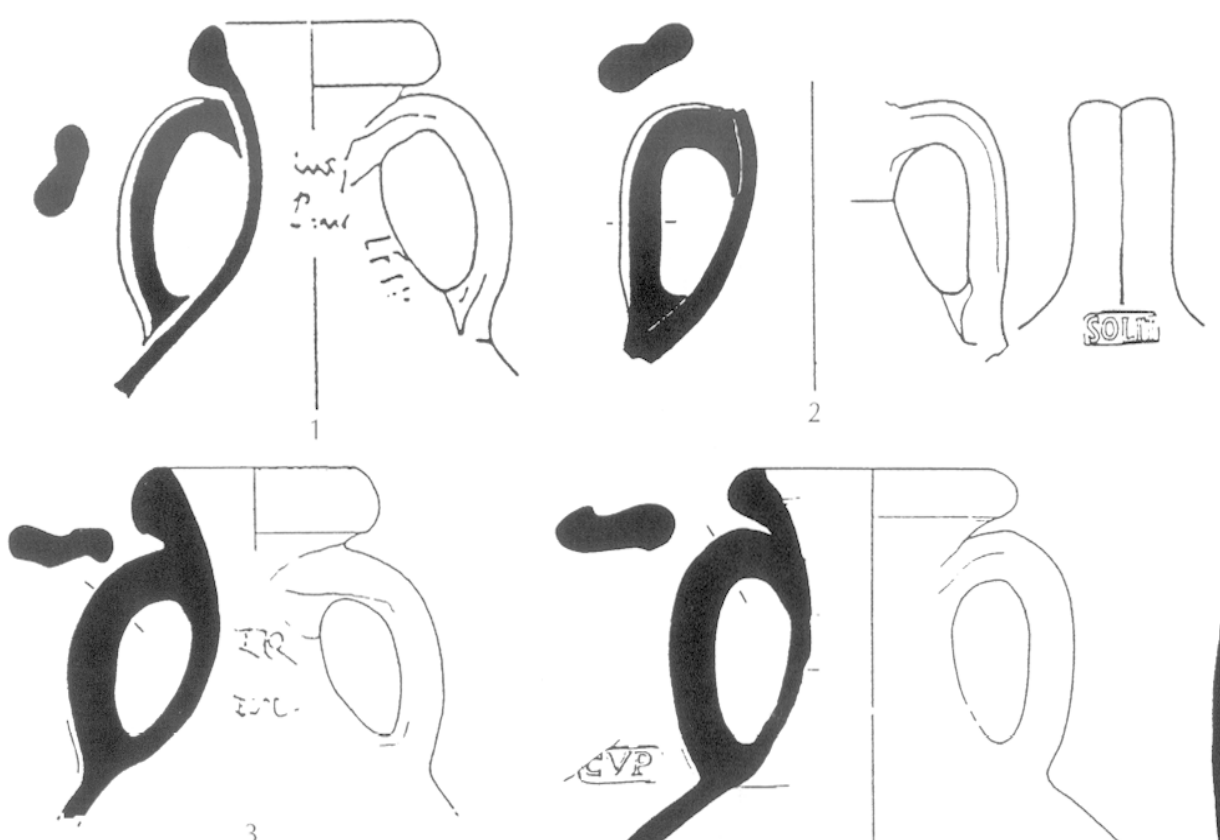

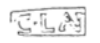
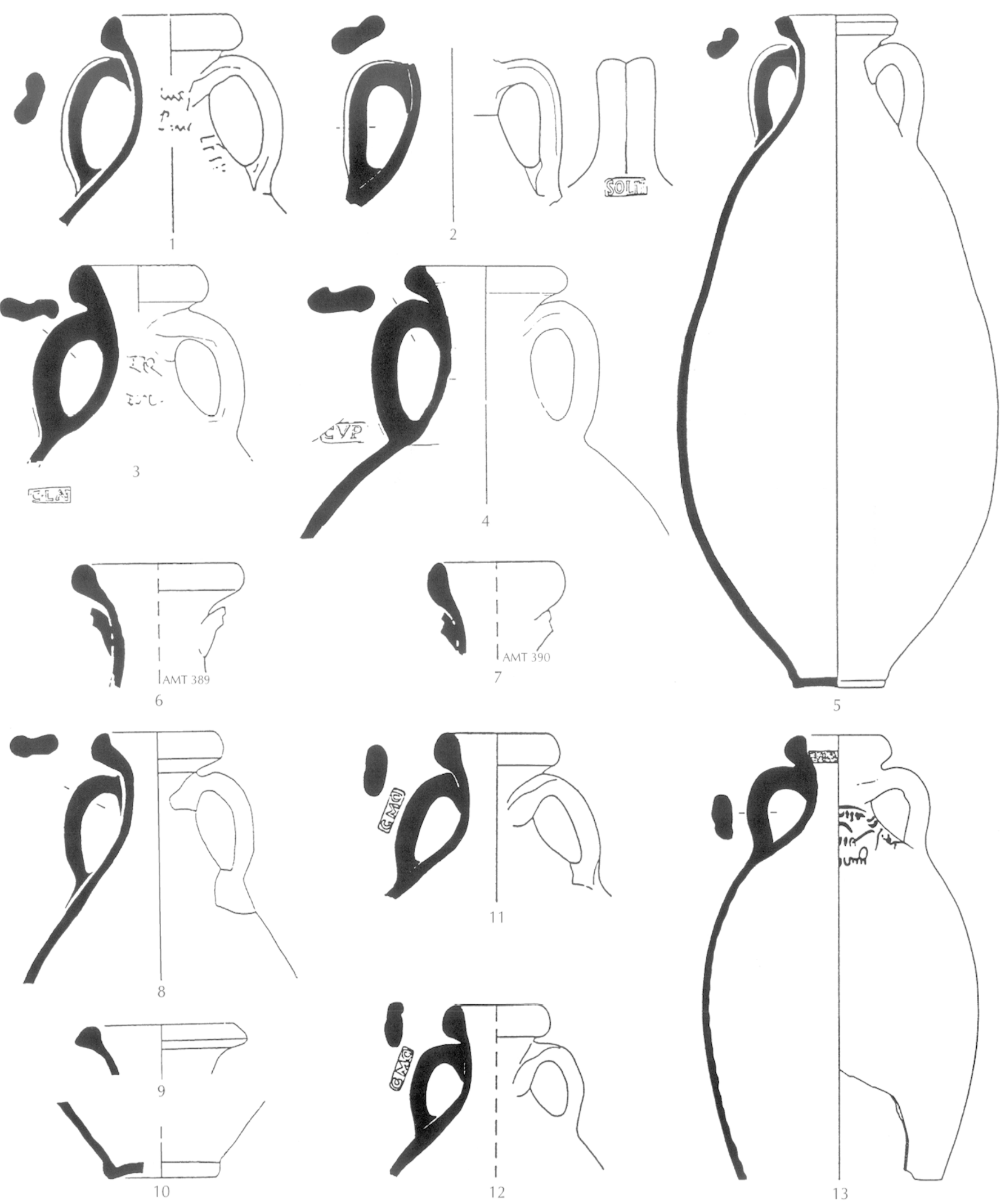

Pl. 27. Amphores de lype 4B: 1, Roanne ; 2, Lyon, Trion ; 3, Augst ; 4, Vindonissa ; 5, Lyon, rue des Farges ; 6, 7, Lyon, Bas-de-Loyasse ; 8-10, Lyon, place Valmy; 11, 12, Lyon, Hauts-de-Saint-Just ; 13, Chalon-sur-Sâne (échelle: 1/4). 

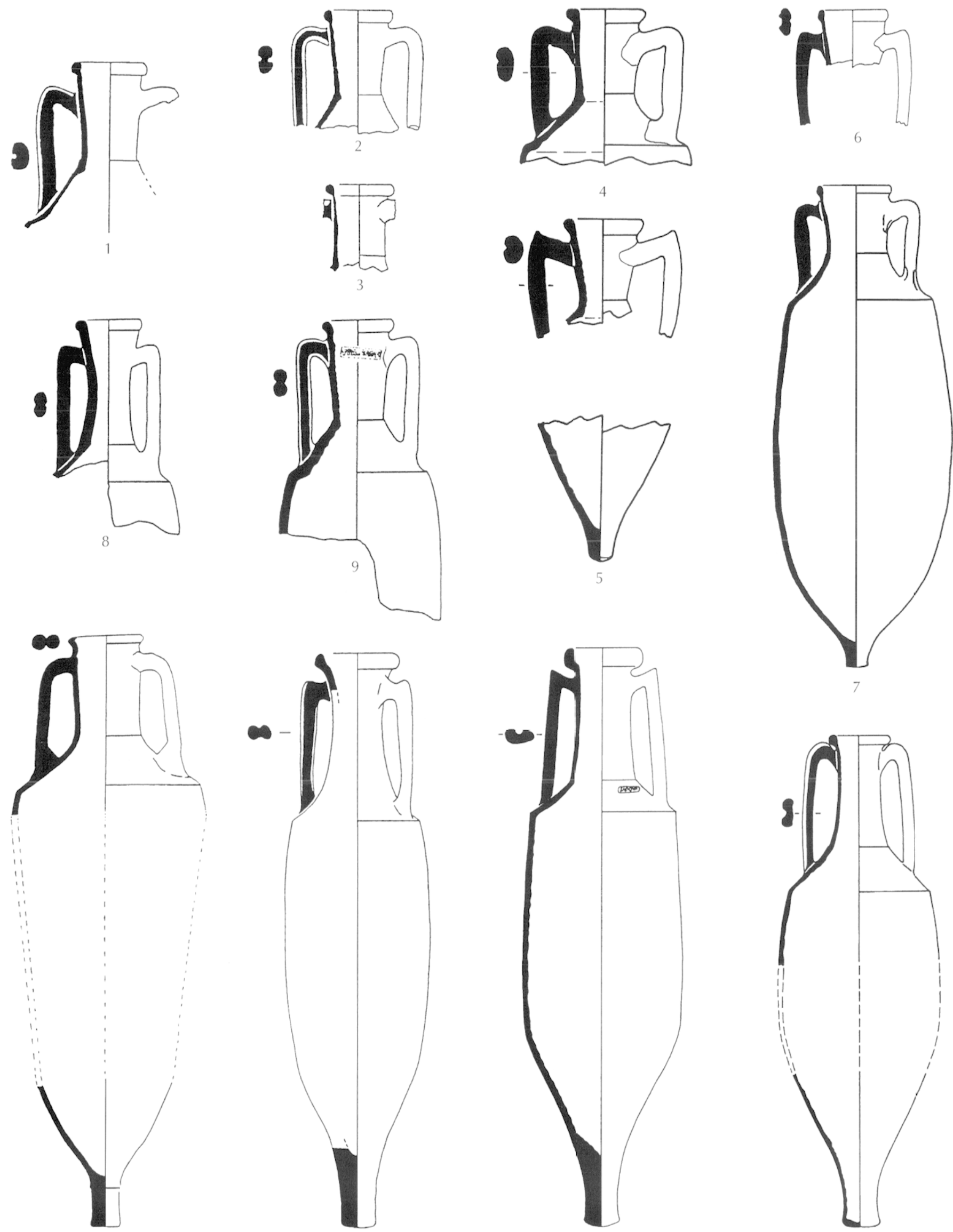

10

11

12

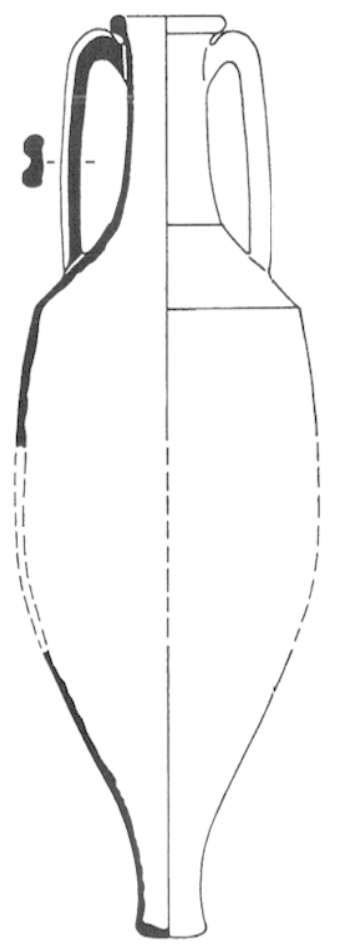

13

Pl. 28. Diverses formes d'amphores Dressel $2 / 4$ produiles en (iaule: 1, 2, Velaux (Tchernia, Villa, 1977); 3, Marseille (Bertucrhi, 1990) ; 4, 5, Le Castellet (Laubenheimer, 1989a); 6, Ponteilla (Laubenheimer, 1989a) ; 7, Sainte-Cécile-les-Vignes (Meffre, Meffre, 1992) ; 8, 9, Corneilhan (Laubenheimer, 1985); 10, 11, Fréjus (Gebara, Béraud, 1996); 12, 13, Crouzilles-Mougon (Schweilz et al., I986), (échelle: $1 / 10)$. 